\title{
Modern Vertical Deformation above the Sumatran Subduction Zone: Paleogeodetic Insights from Coral Microatolls
}

\author{
by Judith Zachariasen*, Kerry Sieh, Frederick W. Taylor, and Wahyoe S. Hantoro
}

\begin{abstract}
Coral microatolls from the coast and outer-arc islands of Western Sumatra retain a stratigraphic and morphologic record of relative sea-level change, which is due in large part to vertical tectonic deformation above the Sumatran subduction zone. Low water levels, whose fluctuations produce measurable changes in coral morphology, limit the upward growth of the microatolls. Annual rings, derived from seasonal variations in coral density, serve as an internal chronometer of coral growth. The microatolls act as natural long-term tide gauges, recording sea-level variations on time scales of decades. Field observations and stratigraphic analysis of seven microatolls, five from the outer-arc islands and two from the mainland coast, indicate that the Mentawai Islands have been submerging at rates of $4-10 \mathrm{~mm} / \mathrm{yr}$ over the last four or five decades, while the mainland has remained relatively stable. The presence of fossil microatolls up to several thousand years old in the intertidal zone indicates that little permanent vertical deformation has occurred over that time. Thus, most of the strain accumulated in the past few decades represents interseismic deformation that is recovered during earthquakes. Elastic dislocation models using these submergence data suggest that elastic strain is being accumulated in the interseismic period and that the subduction zone in this region is fully coupled.
\end{abstract}

\section{Introduction}

Understanding earthquake recurrence and rupture characteristics is hampered by a paucity of data. Accurate characterization of earthquake processes requires knowledge of the temporal and spatial pattern of past earthquakes. Unfortunately, the historical and instrumental records of earthquake occurrence and associated coseismic and interseismic deformation are limited. Seismological records are only available for the past century. Instrumental geodetic records are similarly short and are sparsely distributed geographically. Historical records of seismic shaking are sporadic and dependent on the degree of human development in the region. In few places is the historical record of seismic activity and geodetic deformation complete through even one earthquake cycle (Sieh, 1996). Traditional paleoseismic techniques yield information about the timing of prehistoric earthquakes and, to a lesser extent, about coseismic offset and average slip rate, but rarely allow temporal resolution of events better than a few decades. Precise paleogeodetic reconstruction of deformation during an interseismic period has not been attempted prior to this work.

Previous investigations by Taylor et al. (1987) and Edwards et al. (1988) gave us hope that coral "microatolls,"

*Current address: Institute of Geological and Nuclear Sciences, 69 Gracefield Rd, Gracefield, Lower Hutt, New Zealand. which record fluctuations in relative sea level, might provide a more complete measure of coseismic and interseismic deformation over a subduction zone than has been heretofore possible. They showed that uplift associated with two modern earthquakes could be dated with uncertainties of only a few years.

In this article, we examine the recent displacement history at the Sumatran subduction zone using living corals as a "coral tide gauge." The purpose of the examination is twofold. First, we examine the feasibility and limitations of using microatolls as a geodetic tool. We use living corals because the age of their annual bands can be constrained well, and they are more abundant and less disturbed than fossil corals. This work on living corals provides a basis for similar studies using fossil corals (Zachariasen et al., 1999). Second, we use the method to produce a history of relative sea-level change over the past few decades, documenting ongoing modern vertical deformation from the outer-arc rise to the west coast of Sumatra.

Coral microatolls of the type that record sea-level fluctuations thrive in the equatorial waters of Western Sumatra, and the area lies above a major subduction zone that has been the site of two giant nineteenth-century earthquakes (Newcomb and McCann, 1987). Observations from subduction zones in Alaska and Japan suggest that such earthquakes 
should be accompanied by significant vertical deformation at the surface over the rupture segment (e.g., Plafker, 1965; Plafker and Rubin, 1967; Sato, 1970; Inouchi and Sato, 1975; Kato and Tsumura, 1979). Similarly, interseismic strain accumulation may also produce measurable vertical displacements at the surface (e.g., Savage, 1983; Savage and Plafker, 1991; Savage and Thatcher, 1992; Savage, 1995). Thus, we hoped to see such displacements recorded as sealevel changes in the corals of western Sumatra. Since each microatoll can ostensibly serve as a sea-level recorder, these corals may offer a dense array of sea-level records that could provide a more complete measure of deformation over a broad region than has yet been measured above a subduction zone. The methods could then be applied to fossil corals, which can be precisely dated with U-Th geochronometry (Zachariasen et al., 1999). Records from modern and fossil corals together can constrain the long-term history of vertical displacements above the subduction zone before, during, and after earthquakes.

\section{Geological and Tectonic Setting of Western Sumatra and the Mentawai Islands}

The island of Sumatra, within the Indonesian archipelago, sits atop the Southeast Asian plate, which overrides the subducting Australian and Indian plates (Fig. 1). The Australian and Southeast Asian plates are converging at a rate of $67 \pm 7 \mathrm{~mm} / \mathrm{yr}$ (Tregoning et al., 1994). The $\mathrm{N} 11^{\circ} \mathrm{E} \pm$ 4 convergence direction results in dextral-oblique convergence at the latitude of Sumatra. Several studies (Fitch, 1972; McCaffrey, 1991, 1992) have suggested that the convergent strain is largely partitioned between near-orthogonal subduction at the trench and right-lateral strike-slip along the Great Sumatran Fault (GSF), which runs the length of Sumatra and is subparallel to the trench. Earthquake hypocenters and moment-tensor solutions of several earthquakes suggest that dip of the subduction zone is shallow $(<15$ degrees) near the trench and below the outer-arc rise (about $100 \mathrm{~km}$ from the trench) and steepens to near 50 degrees below the volcanic arc and GSF (about $250 \mathrm{~km}$ from the trench) (Newcomb and McCann, 1987; Fauzi et al., 1996; Harvard CMT catalogue).

Both the subduction zone and the GSF have generated large historical earthquakes. The two largest, $M_{\mathrm{w}}>8.4$, appear to have been produced by rupture of adjacent sections of the subduction zone in 1833 and 1861 (Newcomb and McCann, 1987) (see Fig. 1). There have also been numerous smaller $\left(M_{\mathrm{w}}<7.5\right)$ subduction-zone events. The GSF has produced several historical earthquakes with $8>M_{\mathrm{w}}>7$ since 1892 (e.g., Katili and Hehuwat, 1967).

Most of the field work for this project was conducted in the Mentawai Islands, an island chain that trends parallel to the west coast of Sumatra, about $100 \mathrm{~km}$ from the mainland coast and $80-130 \mathrm{~km}$ from the trench (see Fig. 1). The islands, composed primarily of deformed accretionary-prism sediments and coralline limestone, are the subaerial expres-

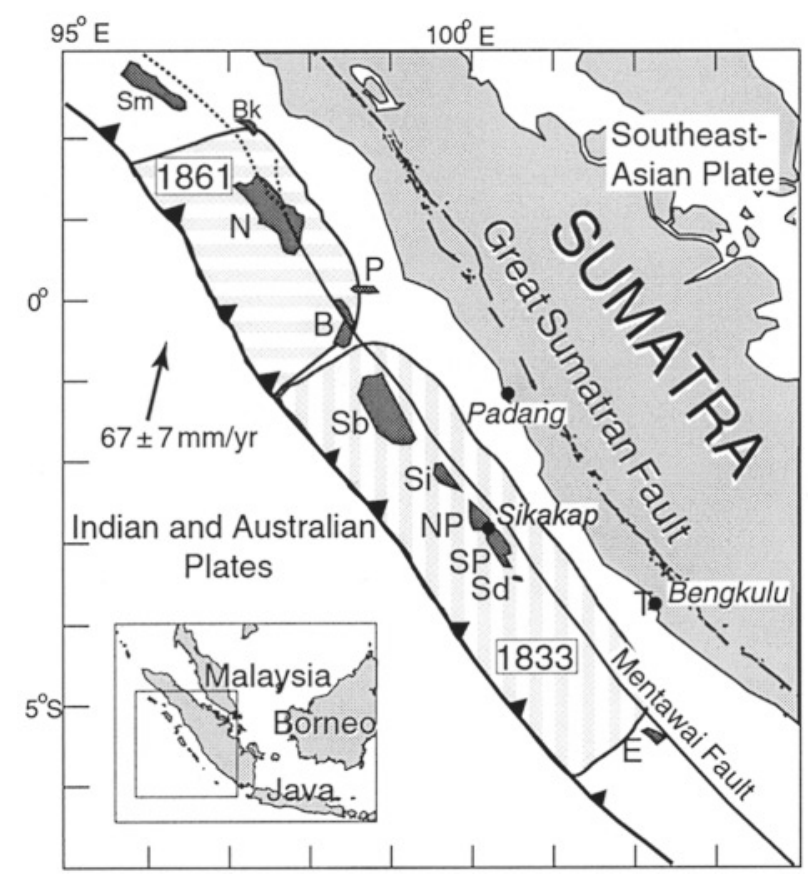

Figure 1. Map of the obliquely convergent Sumatran plate boundary. Surface projections of inferred rupture zones of the two most recent giant subduction-zone earthquakes, in 1833 and 1861, appear with striped patterns (after Newcomb and McCann, 1987). Field work for this project was carried out on four islands in the Mentawai chain: Sipora (Si), South Pagai (SP), North Pagai (NP), and Sanding (Sd), and on Tikos Island (T), west of the city of Bengkulu on the west coast of Sumatra. Other islands in the Mentawai chain include Simeleue (Sm), Banyak (Bk), Pini (P), Nias (N), Batus (B), Siberut (Sb), and Enganno (E).

sion of the crest of the outer-arc rise (Budhitrisna and Andi Mangga, 1990). Field work was concentrated on the coasts of four of the islands, North Pagai, South Pagai, Sipora, and Sanding, which overlie the center of the inferred source region for the $1833 M_{\mathrm{w}} 8.9-9.2$ earthquake (Newcomb and McCann, 1987; Zachariasen et al., 1999).

Reportedly Quaternary coralline limestone as high as 50 $\mathrm{m}$ above sea level suggests net uplift of the islands in the Quaternary (Budhitrisna and Andi Mangga, 1990). MidHolocene fossil microatolls occur less than $2 \mathrm{~m}$ above their modern counterparts. Models of Holocene global hydroisostatic adjustment to deglaciation suggest that sea level in this area reached a maximum of 2-3 m above present about 5000 years ago (Peltier and Tushingham, 1991; Lambeck and Nakada, 1990; W. Peltier, written communication, 1995). Because the magnitude and direction of the observed change in relative sea level recorded by the microatolls is the same as the modeled sea-level change, we conclude that there has been little, if any, net vertical displacement in the Holocene (Zachariasen, 1998; Zachariasen et al., 1999). This may be in contrast to the displacement history of Nias Island, which overlies the 1861 source region (see Fig. 1). Vita-Finzi and 
Situmorang (1989) found elevated coral terraces and platforms on Nias, which they inferred had resulted from coseismic uplift rather than from mid-Holocene sea-level highstand alone.

\section{Coral Microatolls}

Certain genera of coral, which live in abundance in Sumatra, are known as "head" corals. They begin growth with the attachment of a single polyp to a rocky or sandy substrate. Subsequent growth is approximately hemispherical, with new skeleton accreting onto the existing head in concentric shells. The growth rates of head corals, which range from a few millimeters per year to 1 or 2 centimeters per year (Knutson et al., 1972; Taylor et al., 1987; Priess et al., 1995; and this study), depend on a variety of factors including species, water temperature, water depth, turbidity, salinity, available nutrients, and pollutants (Buddemeier et al., 1974, Scoffin and Stoddart, 1978). Growth rates are commonly distinguishable in the head corals because seasonal climatic changes produce density variations in the coral skeleton that appear as annual growth bands, similar to tree rings (Weber and White, 1977; Scoffin and Stoddart, 1978; Lough and Barnes, 1990) (Fig. 2).

The head coral grows upward and outward until it reaches its upward limit of growth, at which point the portion of the coral exposed above this limit begins to die. This upward limit, above which the degree of exposure becomes fatal, is defined as the highest level of survival (HLS). The head corals develop into "microatolls" when their tops reach HLS and are exposed. The term "microatoll" was coined to describe corals or colonies of coral with dead, flat tops and a live outer edge (Scoffin and Stoddart, 1978; Stoddart and Scoffin, 1979).

HLS is controlled by a combination of subaerial exposure, sunlight intensity, and perhaps water temperature (Scoffin and Stoddart, 1978; Taylor et al., 1987), although the specific nature of these controlling factors is not well understood. The elevation of HLS relative to sea level is not strictly defined and varies according to genus or species. Nevertheless, it appears that HLS "tracks" lowest low water levels with a sensitivity of a few centimeters. In the Mentawai Islands, the variation of HLS elevation within a single Porites coral head is usually less than $\pm 3 \mathrm{~cm}$, while the variation of average HLS elevation between microatolls from the same location is about $10 \pm 5 \mathrm{~cm}$ (Zachariasen, 1998). The sensitivity of corals to exposure under various seasonal climatic and weather conditions, and the relationship of HLS to sea level have been discussed in detail by Taylor et al. (1987).

Local water level controls the coral growth. Therefore, local phenomena can produce emergence and submergence signals in coral heads. These include compaction or erosion of the substrate below the coral and ponding of water behind coralline or clastic ramparts. Storms, anomalously strong

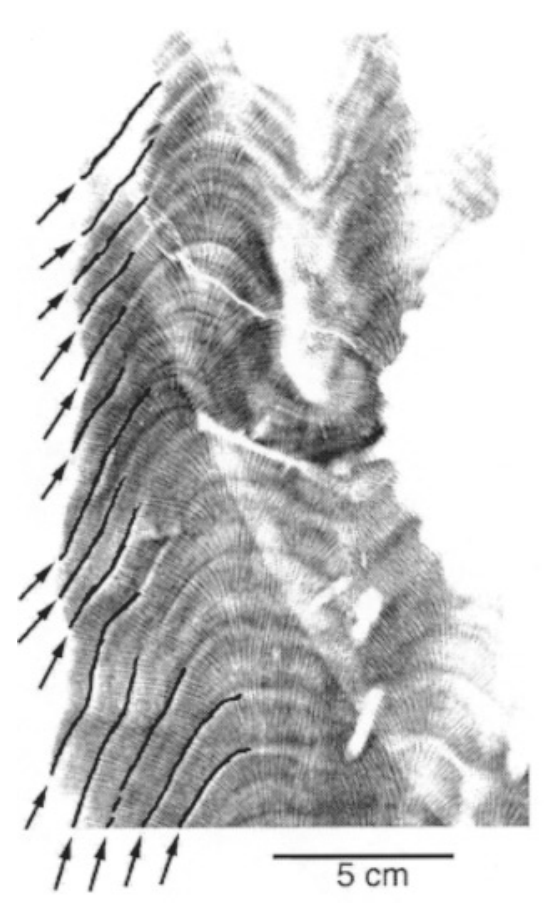

Figure 2. Photo positive of an x-radiograph from a Porites microatoll illustrates the annual bands caused by seasonal density variations. The darker bands, identified with arrows and partly traced with pen, are denser than the light bands.

wave action, and tsunami can tilt or transport microatolls. Scoffin and Stoddart (1978) discuss the effects of these phenomena on coral growth and how to distinguish them.

The tectonic value of the coral heads lies in their retention of an internal record of changes in HLS, and by inference, in sea level. A sea-level change produces a concomitant change in the morphology of the microatoll as it adjusts its growth to the new upper limit. At the same time, the annual growth bands provide an internal chronometer. The morphological expression of HLS change and the coral clock together produce an annual record of sea-level change that is retained within the coral skeleton even after its death. Figure 3 illustrates the changes in coral morphology that changes in sea level can produce. Ideally, the internal stratigraphy of a microatoll would enable one to generate a sealevel history for the time during which the coral lived (Fig. $3(\mathrm{~g}))$. From that sea-level history, one could then infer a history of vertical displacement.

Coral microatolls record HLS; they do not, by themselves, distinguish the cause of sea-level change. Corals may record oceanographic, climatic, or geodynamic signals as well as tectonic ones. Geodynamically and oceanographically induced sea-level changes may be distinguishable from tectonically induced changes by virtue of the magnitude, shape, duration, and extent of the perturbation as well as the tectonic setting (Taylor et al., 1987; Zachariasen, 1998). 
a.

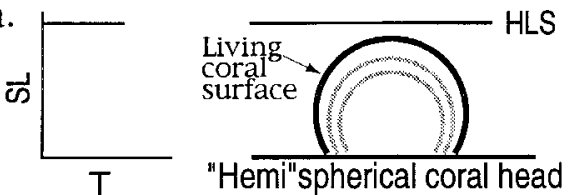

c.

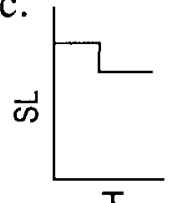

$\mathrm{T}$

e.

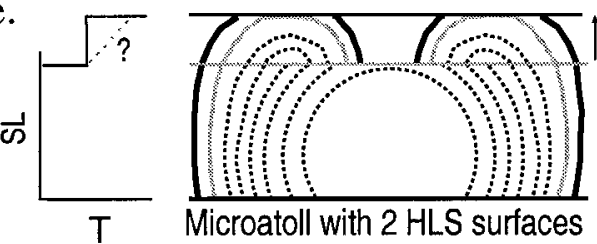

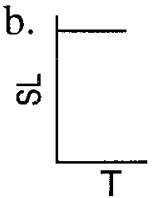

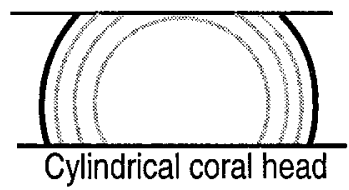

d.
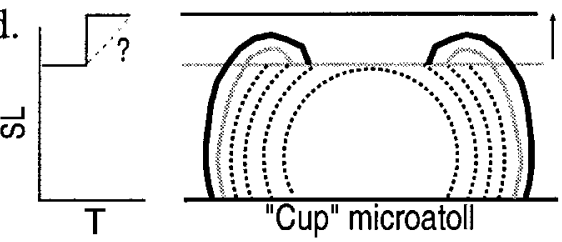

f.

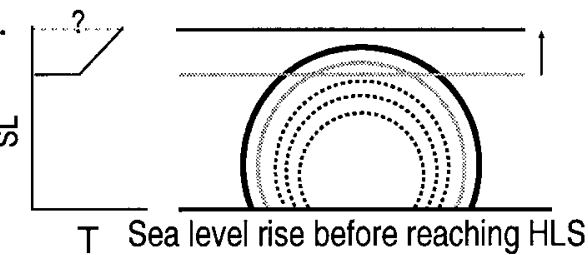

g.
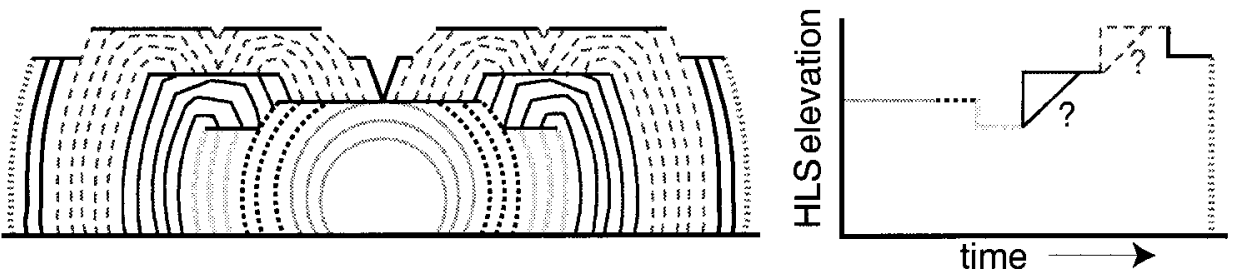

Figure 3. Idealized diagrams of coral growth in response to sea-level (SL) changes. The heavy black ring is the living coral band. The thinner gray rings are dead coral that grew under the same sea-level conditions as the living. The dashed black rings are dead bands that grew under different, older sea level conditions. Modified from Scoffin and Stoddart (1978). (a) The coral has grown in unimpeded (hemi)spherical shape while below HLS. The coral does not record SL while below HLS. (b) Once the coral head has reached HLS, upward growth cannot occur, but the head develops a microatoll morphology by continuing to grow laterally. (c) If SL drops and then stabilizes, the coral will emerge partially above HLS. The exposed part of the coral will die. Lateral growth below the new HLS will continue, producing a lower outer rim around a higher center and a "hat" morphology. The elevation difference between the two HLS flats is a measure of the magnitude of emergence. (d) If SL rises after the coral has reached HLS, upward growth of the coral is no longer impeded. The coral will grow outward and upward to a level governed by coral growth rate, producing a raised outer rim. This "cup" morphology is indicative of submergence. Either a sudden submergence (solid line on the SL curve) or a gradual submergence (dashed and queried line) would produce this morphology. (e) If SL rises and then stabilizes, the "cup" microatoll will eventually reach the new, higher HLS and be once again constrained to grow only laterally. Both the outer ring and the inner ring may be alive. If the inner ring stays alive, the coral may grow inward until it completely covers the old HLS surface in the center. (f) If SL is rising more rapidly than the coral is growing upward, the head will not record changes in HLS. (g) Schematic cross section through a hypothetical coral head. The flat surfaces are HLSs. The rings illustrate the morphology that develops from growth under conditions of fluctuating HLS. The graph is the SL curve that can be inferred from the coral head. The lines with question marks offer another equally plausible SL history.

\section{Previous Work}

Microatolls have been used to document sea-level changes associated with climate change. Woodroffe and McLean (1990) studied slabs cut from living Porites microatolls at several sites in the Indian and Pacific Oceans to obtain annual records of sea-level fluctuations over the last few decades. The analysis of living and dead microatolls has been utilized successfully in the southwest Pacific to document tectonic uplift (e.g., Taylor et al., 1987, 1990, 1992; Edwards, 1988; Edwards et al., 1988). In Vanuatu, significant uplift events were documented using partially emerged living coral microatolls (Taylor et al., 1987). The fact that the dates of these events correspond to those of known earthquakes supports the hypothesis that the HLS changes were 
produced by tectonic uplift. These studies demonstrate that coral microatolls could be used successfully to document the time and amount of uplift associated with recent earthquakes.

\section{Effects of Water-Level Fluctuations on HLS}

To test the fidelity with which HLS changes within a coral microatoll reflect sea-level changes, Woodroffe and McLean (1990) compared the HLS record in corals of Tarawa Atoll in the western Pacific ocean to the three-month running mean of a 15 -year tide-gauge record there. The timing and sign of sea-level changes was consistent between the two records, but the magnitude of the change was more subdued in the microatoll record than in the tide-gauge record. The lack of a similar long-term tide-gauge record in the Mentawai Islands precludes such a direct comparison. The nearest relatively long-term Indian-Ocean tidal record to the Mentawais is from the Cocos Islands $\left(12^{\circ} 7.0^{\prime} \mathrm{S} / 96^{\circ}\right.$ $54.0^{\prime} \mathrm{E}$; about $1000 \mathrm{~km}$ SSE from the Pagais), a tectonically stable atoll in the eastern Indian Ocean (Woodroffe et al., 1991) (Fig. 4; University of Hawaii Sea Level Center SILPPac database, http://uhslc.soest.hawaii.edu/uhslc/data.html; hereafter UHSLC database). We use the Cocos record to examine how a coral in the Mentawais might be affected by sea-level fluctuations with and without tectonic influences.

Figure 4(a) shows hypothetical coral growth at $10 \mathrm{~mm} /$ yr under Cocos sea-level conditions. In a tectonically stable area like the Cocos Islands, the only causes of sea-level change are oceanographic/climatic and glacio-isostatic effects. The glacio-isostatic effect there is very slight $(\leq 1 \mathrm{~mm} /$ yr) and short-term oceanographic effects dominate the record (Woodroffe et al., 1990a, 1990b). Lowest low water levels occur about once a year, usually in the first part of the year, and they vary by as much as $25 \mathrm{~cm}$. In the 10 years of the Cocos record, the upward growth of the hypothetical coral was "clipped," or impeded by lowest low water, four times.

Figures 4(b) and (c) show the HLS impingements on corals growing at $10 \mathrm{~mm} / \mathrm{yr}$ if $7 \mathrm{~mm} / \mathrm{yr}$ of emergence or submergence were occurring. The emerging coral is clipped almost every year, and its 1996 HLS height ends up some $13 \mathrm{~cm}$ lower than its 1986 height. The morphology of such a coral would show a gradual outward downstepping. The submerging coral is clipped less often, twice in 10 years. Its HLS was about the same height at the end of the decade as at the start. Microatolls at submerging sites should display less frequent HLS clips than those on stable or emerging coasts. These synthetic histories suggest that Mentawai microatolls should display evidence of non-tectonicallyinduced HLS impingement several times each decade, regardless of whether the islands are submerging, emerging, or stable.

A tide gauge deployed for three years (1987-1990) near Padang on the west coast of Sumatra (see Fig. 1) suggested that relative sea level was rising at an average rate of 3.3 $\mathrm{cm} / \mathrm{yr}$ (UHSLC database). However, there is no other evi- a.
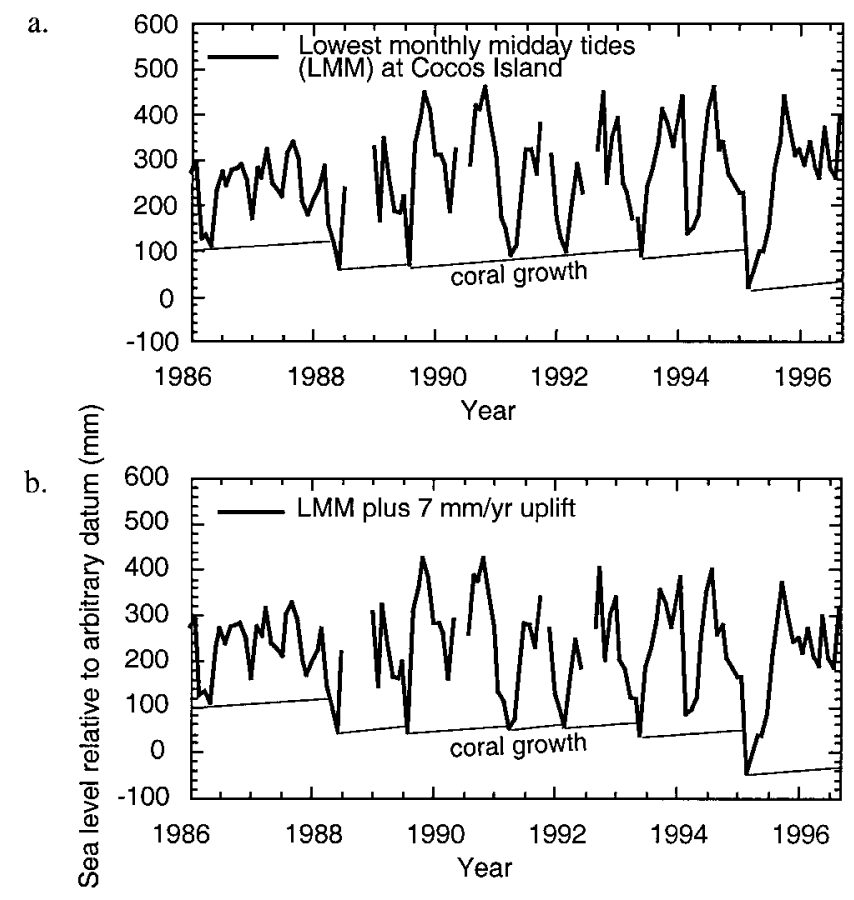

c.

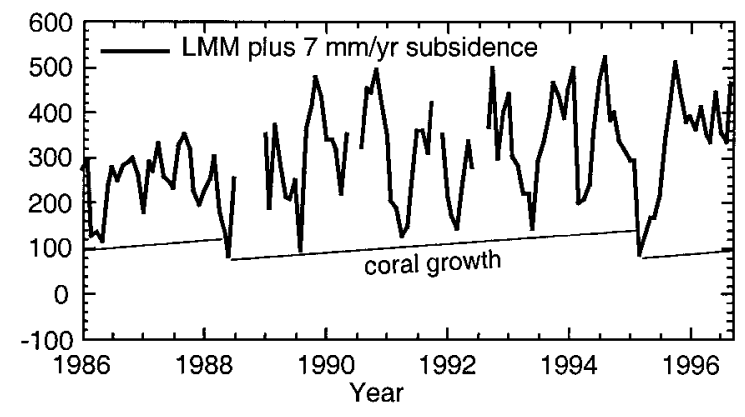

Figure 4. (a) Hypothetical coral growth based on a 10-year Cocos Islands tidal record of the lowest low tide of the day occurring during the midday hours, when emergence of a coral above water is most likely to be fatal and HLS recorded (thick black line). A hypothetical coral, growing near HLS at a rate of $1 \mathrm{~cm} / \mathrm{yr}$ under these tidal conditions, was generated (dashed line). Data from University of Hawaii Sea Level Center database. (b) Similar hypothetical upward growth of a coral as in (a) but with $7 \mathrm{~mm} / \mathrm{yr}$ emergence superimposed on the Cocos record. (c) Similar hypothetical upward coral growth, but with a $7 \mathrm{~mm} / \mathrm{yr}$ tectonic submergence rate superimposed on the Cocos tidal record.

dence that sea level near Padang is rising at that rate long time scales. The tidal range at Padang is about $20 \mathrm{~cm}$.

Sea-level records from two Pacific Ocean sites in Malaysia, near Sumatra, indicate that the deviation of average monthly sea level from the mean annual cycle of sea-level variation between 1975 and 1995 show anomalously high and low water level at the same time that water level highs and lows occurred at Padang (UHSLC database). This suggests that Padang experienced oceanographic fluctuations in sea level at that time. The Malaysian records are longer than 
Padang's and reveal a number of other anomalously high or low sea-level measurements over the past 20 years, so it is possible that Padang might experience similar-sized sealevel deviations.

\section{Results}

We visited numerous sites around the Mentawai Islands in July 1994 and mid-January to mid-February 1996 (Fig. 5). These sites are between 80 and $130 \mathrm{~km}$ from the subduction-zone trench. In 1996 we also visited Tikos Island, a few kilometers from the town of Bengkulu on the western Sumatran coast (see Fig. 1). This island is about $235 \mathrm{~km}$ from the trench. We observed numerous microatolls at each site to assess the general nature of sea-level change as manifested in the gross morphology of the corals and to assess the degree of variation in gross morphology that might be expected between microatolls that have experienced the same sea-level history.

The Mentawai Islands in this area are currently submerging rapidly. In many locations, salt or brackish water swamps and lagoons contain recently drowned trees rooted below or in the intertidal zone just behind coastal storm berms. The berms themselves have clearly been prograding landward in recent decades, overrunning and burying trees and coral (Zachariasen, 1998). By contrast, a reconnaissance of several sites on the western coast of Sumatra, near Padang and Bengkulu, suggest that submergence is nonexistent or much more subdued than in the Mentawai chain.

The morphology of living microatolls in the Pagai and Sipora Islands is broadly similar. In all locations, the corals manifest a cuplike morphology indicative of submergence (Figs. 6 and 7). Many of the corals are more than a meter tall and have a high height-to-width aspect ratio, suggesting that submergence might be nearly keeping pace with upward coral growth. The width and height of the raised rim(s) varies substantially from coral head to coral head and from site to site. Several corals have multiple sets of rims and flats, stepping up and out, which may indicate episodic submergence and exposure. In general, corals from sites on the west coast of the islands have higher rims than those on the east side. Corals from sites on the easternmost islets in the archipelago southeast of the South Pagai peninsula, e.g., site P96-K, have the most subdued rims of any corals found on the islands. In 1994, most corals showed signs of slight recent submergence, while in 1996, a depressed living ring of coral suggested that a slight emergence had occurred between the two field seasons.

The morphology of corals from Tikos Island is noticeably different from that of corals in the Pagais and Sipora. The microatolls on Tikos do not possess the pronounced raised outer rim that is prevalent on the Mentawai corals. Most corals, even those several meters in diameter, are low, wide, and flat topped, with only $2-4 \mathrm{~cm}$ of relief across the surface. All show a 1994-1995 emergence of a few centi-

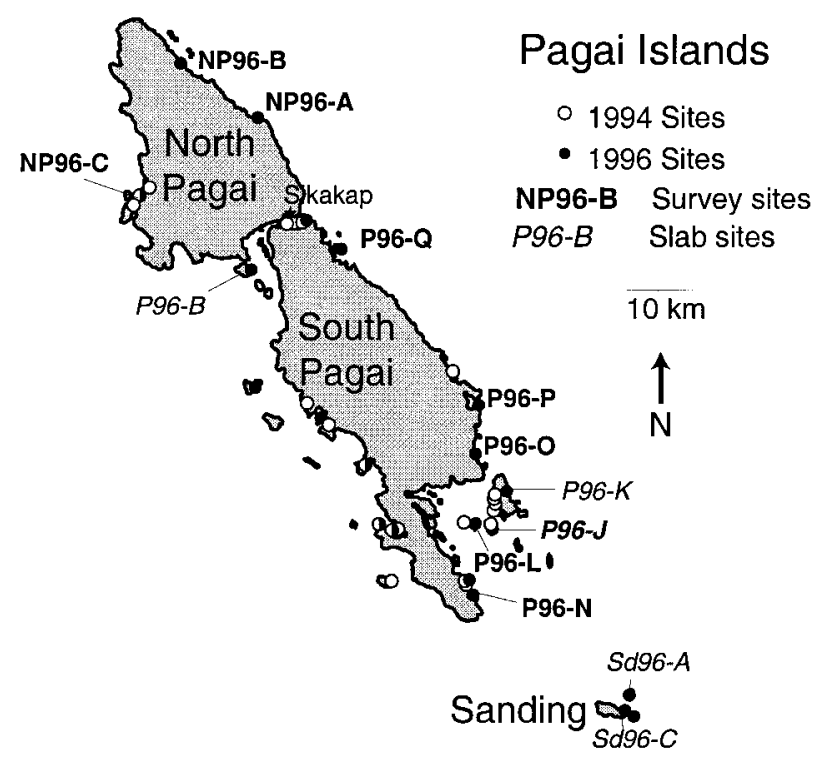

Figure 5. Map of the Mentawai Island sites visited in 1994 and 1996. Sites at which surveys were performed and where we collected slabs of living corals are indicated by name.

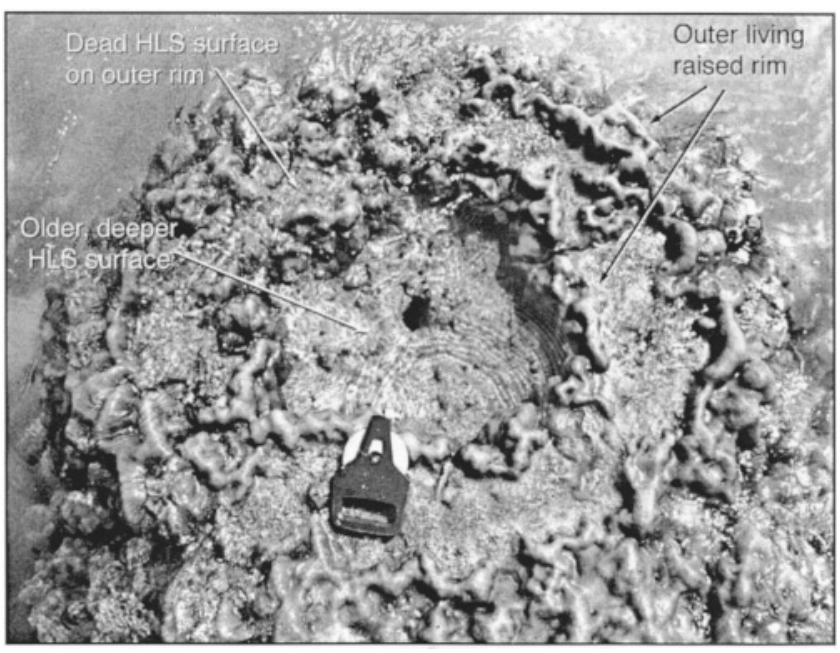

Figure 6. Photo of a submergent coral head from North Pagai, Mentawai Islands. The relationship of the three tiers reflects rising sea level. Photo was taken during the 1994 field season.

meters. Many, though not all, have a small raised ring a few centimeters in from the living ring, as if slight submergence preceded the 1994-1995 emergence. The moderate thickness of coral heads combined with the lack of substantial rim development suggest that sea level (HLS) has been more stable at this site than at the sites on the Mentawai Islands.

\section{Methodology—Analysis of Coral Slab Sd96-C-1}

In 1996, we gathered cross-sectional slabs from five coral heads from the Mentawai islands and two from Tikos 
Island (see Fig. 5). We x-rayed the slabs to reveal the annual growth bands. Most annual bands are $1.0 \pm 0.5 \mathrm{~cm}$ thick.

We describe the stratigraphic analysis of sample Sd96C-1, cut from a living head at site Sd96-C on Sanding Island (see Fig. 5), to illustrate the use of the coral tide gauge. The sample came from a coral about $185 \mathrm{~cm}$ in diameter, with an outer rim about $30-35 \mathrm{~cm}$ above a central flat and $75 \mathrm{~cm}$ above the substrate. The top of the living ring was about 5 $\mathrm{cm}$ below that of the previous ring at the top of the coral indicating that HLS in 1995-1996 had dropped from the year before. The sample includes part of the raised rim and associated outer edge of the coral head and a piece of the large central flat. The $\mathrm{x}$-radiograph of this slab reveals the annual growth bands of varying density (Fig. 8). Each pair of dark (dense) and light (less dense) bands represents one annual ring. Light, less dense bands grow in the rainier season, or the early part of the calendar year, generally before the lowest low tides of the year.
The growth bands and former HLS surfaces or unconformities are depicted graphically in Figure 9. We determined each band's age by counting back from the outside ring, which was alive in early 1996. The outermost ring therefore includes primarily skeletal growth that occurred in calendar year 1995. The elevations of the tops of the annual bands were measured relative to the top of the outer, living ring. Rings that were clipped and impeded from upward growth represent true HLSs. The upward growth of complete rings was limited by the coral's natural growth rate, not by exposure, and therefore the tops of these rings are not HLSs. They do, however, provide a record of minimum HLS, since HLS must have been above the top of the ring.

The lobate nature of the upper surface of the outer rim is an indication that it is a constructional surface, without significant erosional modification. Annual bands taper as they approach the HLS surface or curve without appreciable change in thickness. The truncation of rings and relative a.

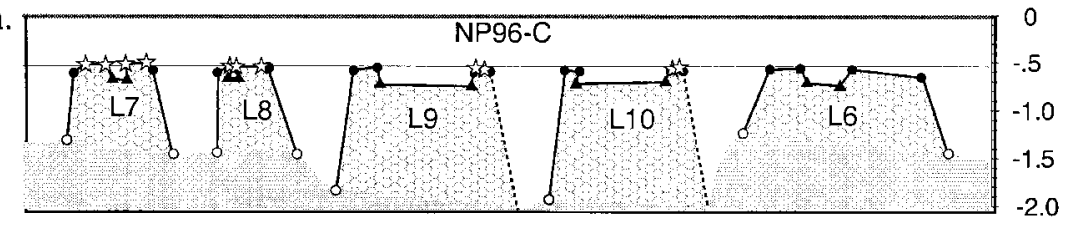

b.
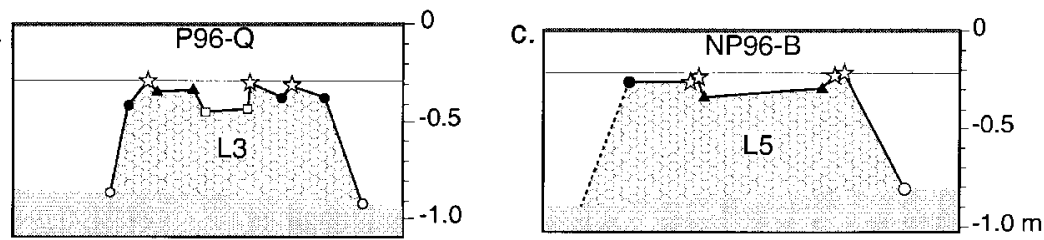

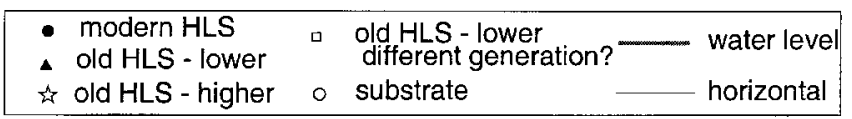

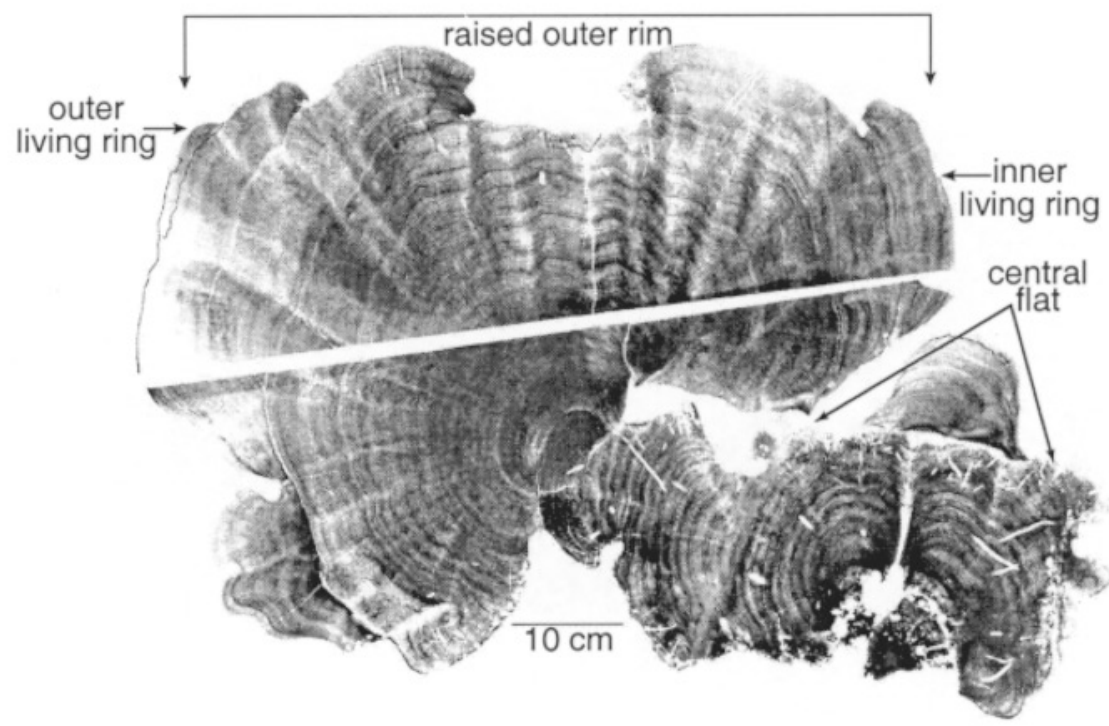

Figure 7. Profiles of living corals at several sites in the Mentawai Islands. Elevations are relative to an arbitrary datum at each site and cannot be compared from site to site. The profiles show only the main HLS surfaces of the coral head and not the details of topography on the heads. All of these microatolls have raised outer rims around central flats. This "cup" morphology is typical of microatolls on submerging reefs.

Figure 8. Photo positive of $\mathrm{x}$-radiograph of sample Sd96-C-1, which was cut from the raised outer rim and part of the central flat of the microatoll. Each light and dark pair is an annual band. Flat surfaces, where lateral growth continues but upward growth does not, are usually old HLS surfaces, marking the elevation at which exposure above sea level has prevented further upward growth. 


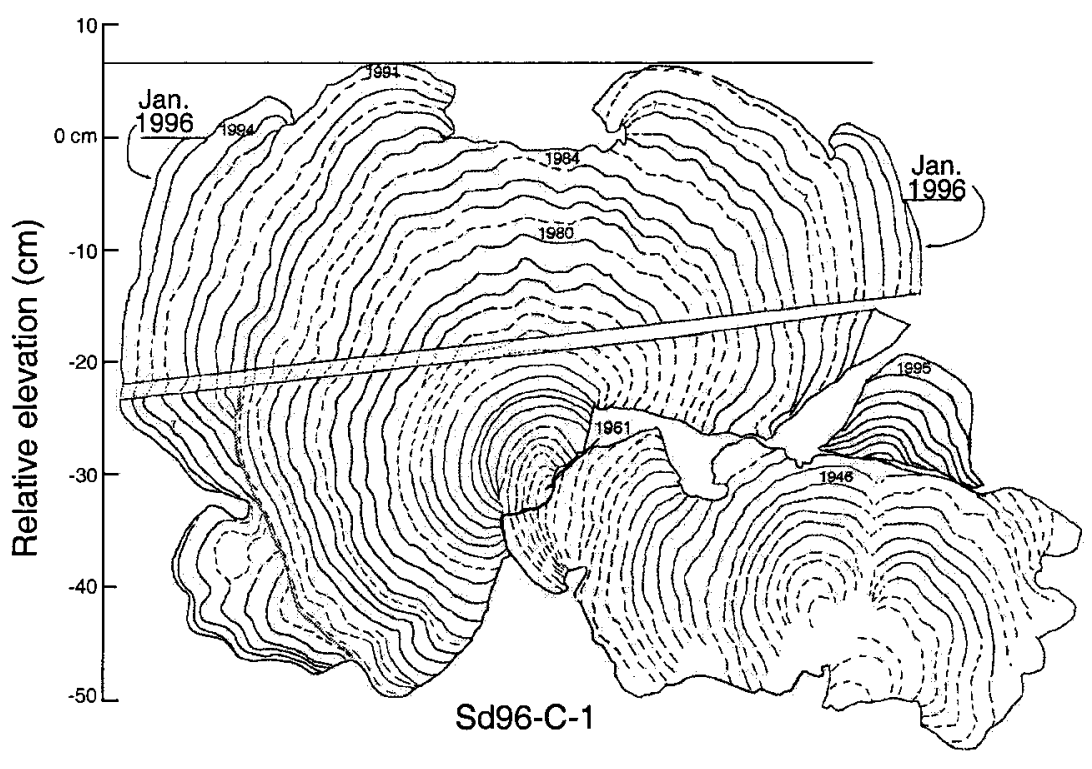

Figure 9. Drawing of sample Sd96-C-1 from the x-radiograph (see Fig. 8). Annual bands are drawn in, solid where clear, dashed where uncertain or diffuse. The lower piece on the right, connected by a small wedge to the higher, outer rim, is a remnant of an old HLS flat which continued farther into the center of the coral but could not be reached with the saw for sampling. The tops of the inner and outer living surfaces are marked "Jan. 1996." The orientation of the older rings is used to estimate the horizontal; the top of the outer living ring is defined as 0 elevation. The straight-edged, angled cut through the middle of the slab is where we cut the slab in two to fit it on the sawing table. About $5 \mathrm{~mm}$ of material, equivalent to the thickness of the saw blade, is missing. smoothness of the top of the central flat indicate that it has suffered some erosion. We suspect that the erosion is primarily biogenic, not mechanical, erosion since the outer rim is uneroded.

Having identified the old HLSs, we combined the ages and elevations of the annual rings and HLS surfaces to produce a plot of HLS versus time. Figure 10 shows HLS histories for Sd96-C-1 and several other slabs that we discuss later. The plots show the highest elevation of each microatoll's annual bands versus their year of formation. We have not made any adjustment for the minor bioerosion of the annual bands that we suspect has occurred on the central flat of Sd96-C-1.

The growth-band record from slab Sd96-C-1 indicates that the coral only occasionally reached HLS. Over the last 10 or 12 years, represented by the uppermost part of the outer rim, HLS fluctuations produced the irregular, sawtoothed surface of the rim. From 1984 to 1985, the coral appears to have been at HLS and to have produced the small, flat surface in the center of the outer rim. Following that period of stability, HLS rose, freeing the coral to grow upward, which it did until 1992 when it dropped several centimeters, to near its 1985 level. It immediately began to grow up again until 1994-1995, at which time it dropped to the level at the time of sampling. This last HLS drop may correspond to the pronounced negative sea-level anomaly that appears in the Malaysian records.

The last two small emergences occurred when the coral was still below HLS. The distance from the top of one ring to the new HLS therefore provides only a minimum measure of emergence. The previous two emergences were followed immediately by regrowth up above the newly established HLS. It is reasonable to expect that the most recent downdrop will be equally short-lived. There have been no signifi- cant earthquakes in the area that might indicate a tectonic source for the emergence (Harvard CMT catalogue).

The sea-level stability implied by the last decade of coral growth is not representative of earlier parts of this coral record. The 1984-1985 growth at HLS was preceded by at least 20 years of growth below and unimpeded by HLS. The presence of the large, central flat some $30 \mathrm{~cm}$ below the top of the outer rim testifies to significant submergence just before or during these two decades of unimpeded growth. The fact that HLS did not clip the surface at all in this 20-year period suggests that the submergence may have been sudden rather than gradual, such that HLS rose about $30 \mathrm{~cm}$ in 1960 and upward coral growth did not again reach it until 1984. However, gradual submergence at a rate at or slightly above the natural coral growth rate is also a possible explanation, as are submergence histories intermediate between these two end members.

Uncertainties exist in both age and elevation estimates based on slab stratigraphy. Occasionally indistinct rings generate uncertainty in ring identification and hence uncertainty in age and elevation. Erosion may introduce uncertainty in elevation measurements that is not easily quantifiable. Errors arise in orienting the slab with respect to horizontal. The variation in horizontal as determined by matching rings of equal age across a flat is a function of the variability in living HLS height, which is about $\pm 4 \mathrm{~cm}$ (Zachariasen, 1998). We estimated horizontal in Sd96-C-1 by using an average of the lines across the tops of annual bands from the last decade. Because of the interdependency of age and elevation, and the difficulty in quantifying and combining each contributing error, the overall error is not shown in the plot of HLS history (see Fig. 10). Nevertheless, a qualitative assessment of those errors indicates that the combined error in most cases will be less than $5 \mathrm{~cm}$ in elevation and \pm 5 years in age in a 50-year sample. 


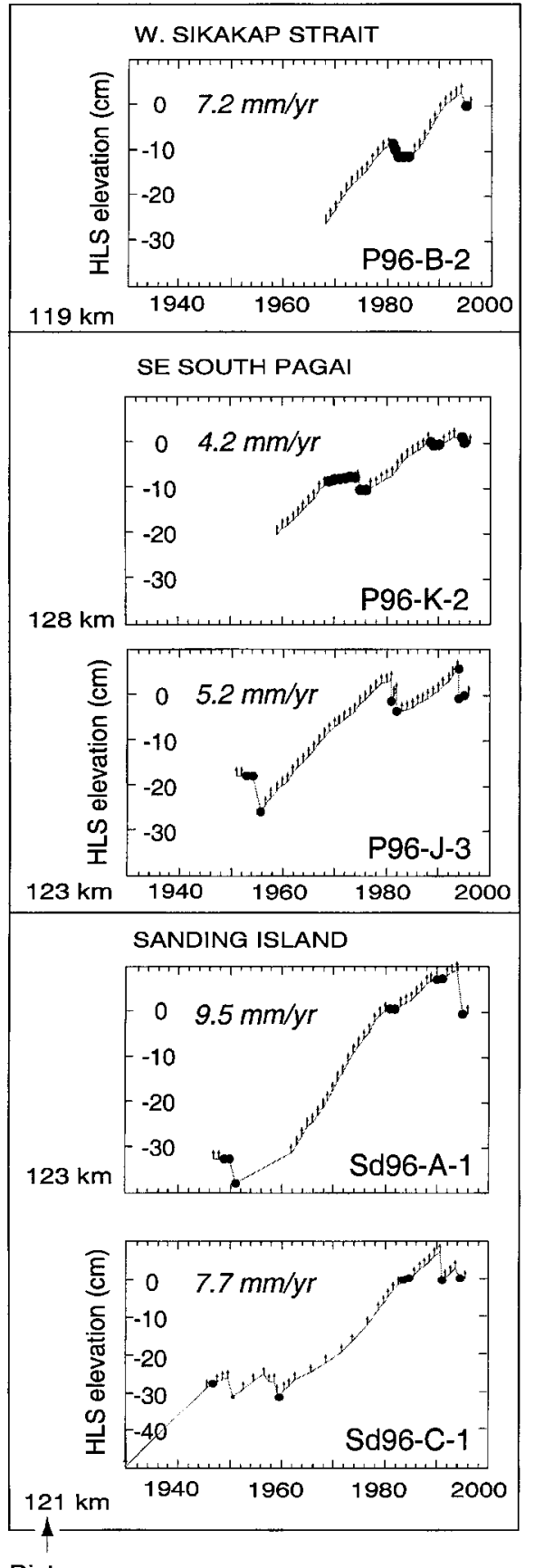

Distance

from trench

\section{Coral Slab Stratigraphy}

We performed similar analyses of x-rayed slabs for six other samples. Cross sections of these slabs appear in Figure 11. Plots of HLS elevation versus time for these samples and Sd96-C-1 appear in Figure 10.

Mentawai Islands. The four other samples from the Mentawai Islands were broadly similar to Sd96-C-1. Each coral head showed the cup shape indicative of submergence, with a central flat surrounded by a raised rim. The living rim of each in 1996 was also several $\mathrm{cm}$ lower than the top of the outer raised rim, consistent with a small drop in HLS between
Figure 10. HLS curves derived from Figures 9 and 11. The dots show the elevations of actual HLS surfaces; the arrows mark minimum HLS only. The minima are the elevations of the tops of annual bands whose upward growth appears unaffected by HLS, indicating only that HLS was somewhere above the top of the coral in that year. The rate of submergence displayed for each sample is the slope of a line fit by least squares to the HLS elevations (dots). the 1994 and 1996 field seasons. Stratigraphic analysis of the slabs confirms the gross morphologic interpretations and indicates substantial submergence of the sampled corals within the last few decades, although the details of sea-level history vary between the microatolls.

Sample Sd96-A-1 (Fig. 11(a)) came from Sanding Island near Sd96-C (see Fig. 5). Growth of the outer rim originated a few centimeters below a central flat, in the early to mid-1950s, and proceeded unimpeded until about 1980. After HLS impingement at that time, upward growth continued until 1990 and then resumed again until the HLS drop in about 1995 . 


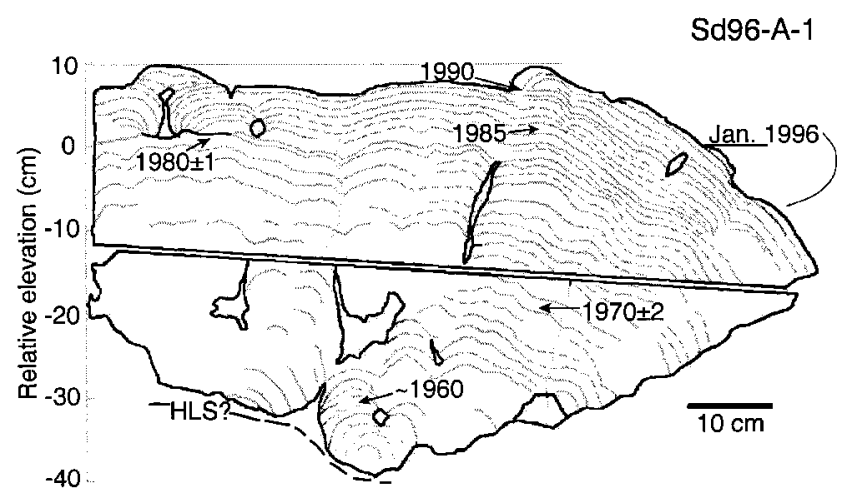

(a)

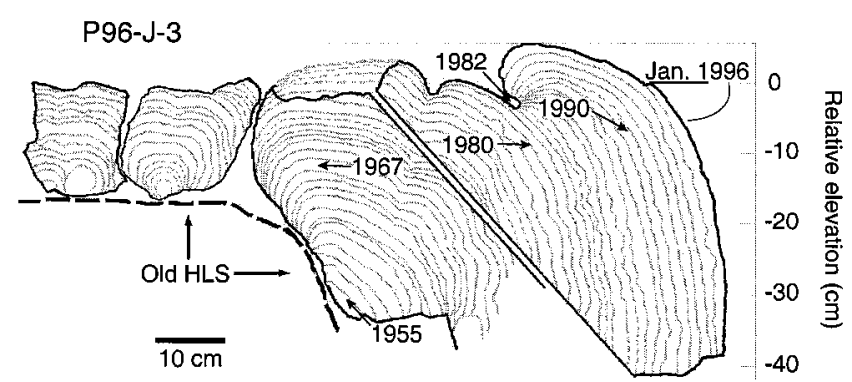

(b)

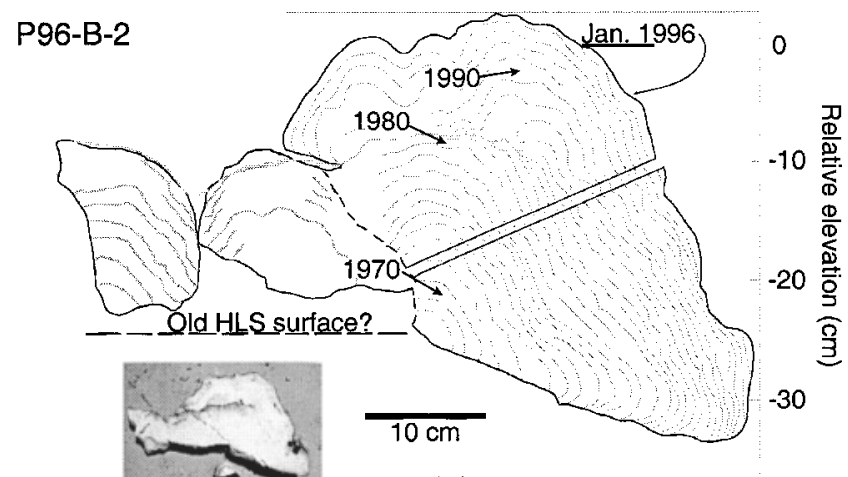

(d)

(e)

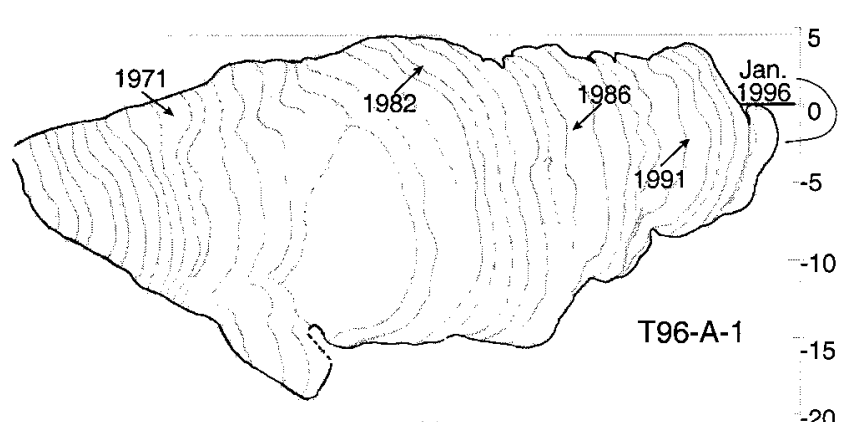

(f)

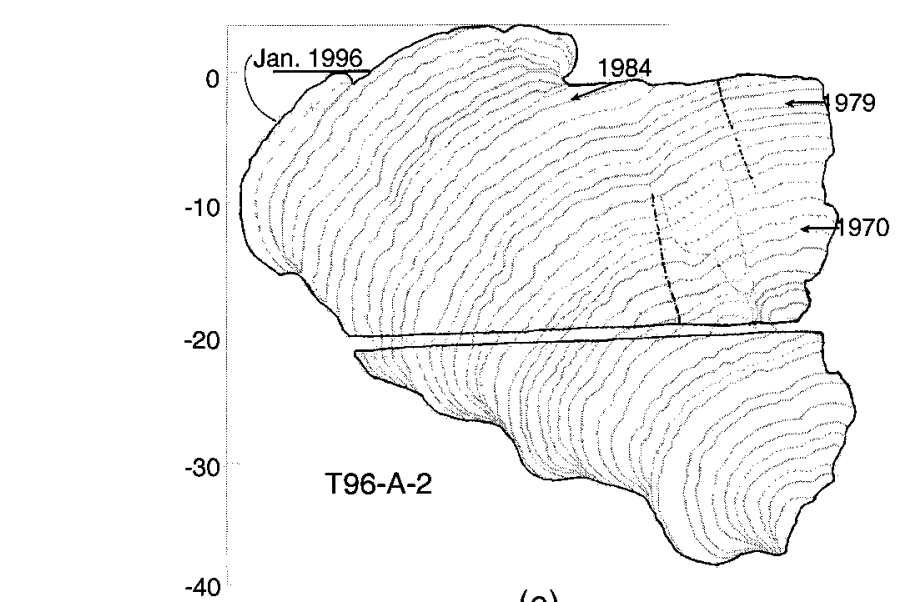

\section{.} 10 $\infty$

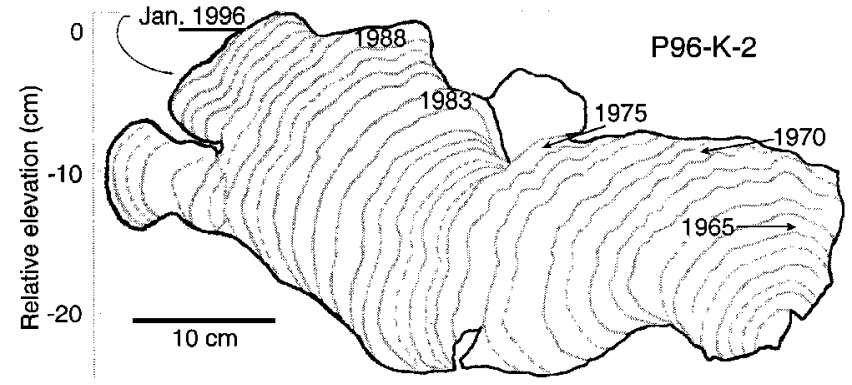

(c) is

Figure 11. Drawings of slabs cut from living corals at several sites around South Pagai, Sanding, and the west coast of Sumatra: (a) Sd96-A-1, (b) P96-J-3, (c) P96-K2, (d) P96-B-2 (inset is photograph of slab), (e) T96-A-2, (f) T96-A-1. The site locations are shown in Figure 5.

P96-J-3 (Fig. 11(b)) was taken from a small islet about $30 \mathrm{~km}$ northwest of Sanding Island (see Fig. 5). Its central HLS flat has been overgrown by the outer raised rim and recolonized by new growth. Growth of the rim began a few centimeters below an unsampled central flat in the mid1950s, near the time of initiation of upward growth in Sd96A-1 and Sd96-C-1. Unimpeded upward growth of the rim continued until an HLS clip in the early 1980s. Net change in HLS since then has been about nil.
P96-K-2 (Fig. 11(c)) was collected a few kilometers north of P96-J-3. At this site, we observed greater morphological variation among the living corals than at the other Mentawai sites. The live Porites corals had smaller raised rims, and the 1995 emergence signal was more subdued. Upward growth of the sample was unimpeded until an HLS clip in 1969. HLS clips at about the same elevation through 1975 created the microatoll's central flat. A slight submergence in 1976 was followed by upward growth of a 10-cm- 
high outer rim began in 1976 and continued through 1988, with a possible clip in 1983. Net change in HLS has been nearly zero in the past decade.

Sample P96-B-2 (Fig. 11(d)) comes from the northwest coast of South Pagai (see Fig. 5) and contains the microatoll's growth history from about 1968. The tight curvature of the oldest rings suggest that the sample is part of an outer raised rim that grew from the periphery of an older, lower HLS surface. The sample provides only a set of rising lower bounds for HLS during the 1970s. It first records HLS in 1980 or 1981 and shows stability or slight emergence over the next three years. The 1995 HLS impingement did not kill the corallites down to the early 1980 s level.

The HLS records from the five Mentawai corals described already are broadly similar, though not identical (see Fig. 10). All display overall submergence over the last several decades. They show little net change in HLS elevation since the early 1980s, with the possible exception of P96$\mathrm{K}-2$. All experienced a drop in HLS in the early to mid1990s, although the magnitude of this die-down differs by several centimeters.

The three long records (Sd96-C-1, Sd-96-A-1, P96-J-3) lack HLS impingements during most of the 1960s and 1970s, although the onset of unimpeded upward growth differs by several years. HLS levels before this period are 20 to $30 \mathrm{~cm}$ lower than after and suggest an episode of submergence beginning in the late 1950s or 1960s. Although P96-K-2 differs morphologically and stratigraphically from the other Mentawai corals and suggests a somewhat different submergence history, at least in magnitude, the HLS record of this coral is not inconsistent with a sudden submergence event occurring in the 1950s. That submergence is recorded in samples P96-J-3, Sd96-C-1, and Sd96-A-1 because they had already reached HLS at least once by that time. P96-K-2 was probably not alive at the time and thus never recorded the submergence event. If the submergence had been gradual over three decades, the coral might have recorded the later years of the submergence. A sudden submergence would not appear at all.

Four of the five records display net HLS stability during the 1980s and 1990s. P96-K-2 displays a period of HLS stability from 1969 to 1976 . This stability may also have occurred at the other sites, but those corals did not record it because they had not yet grown back up to HLS. P96-K-2 displays a $10-\mathrm{cm}$ difference in HLS level that indicates submergence between 1976 and 1989. Like the other Mentawai samples, P96-K-2 shows no net change in HLS since the late 1980 s, but the period of stability began several years later.

Tikos Island-Western Sumatra. Samples T96-A-2 (Fig. 11(e)) and T96-A-1 (Fig. 11(f)) came from the same site on Tikos Island, near the Sumatran coast (see Fig. 1), and they reveal a strikingly different record of HLS change than the corals on the Mentawai Islands.

Stratigraphic analysis of the two slabs bears out the contention that there has been little or no recent submergence on Tikos Island. Both samples came from the outer edge of essentially flat Porites microatolls. Their records are short, but they show more impingements on the surface by HLS in that period than do the Mentawai coral records. They reveal a 1994 emergence of about $4 \mathrm{~cm}$, but older elevation changes are mostly smaller than that. The 1994 emergence in T96A-1 was preceded by minor fluctuations of about $2 \mathrm{~cm}$ or less back to the mid-1970s. T96-A-2 has a flat center representing stable HLS from at least 1980-1986 and possibly longer at an elevation similar to 1996 HLS. Both corals suggest little or no net vertical displacement over the last two to three decades.

T96-A-1 and T96-A-2 have some differences that illuminate the degree to which microatoll stratigraphy can vary even between corals of similar age in the same location. T96A-2 slab reveals a 4-cm submergence between 1986 and 1992 that does not appear in T96-A-1. The presence of a small, raised rim in one sample and its absence in another cannot be ascribed to tectonism or regional oceanographic effects, because the microatolls are only $50 \mathrm{~m}$ apart. If the rise in T96-A-2's HLS represents real submergence, it is very localized and may be due to factors affecting only that coral or a small area around it. Erosion or compaction in the late 1980s of the sandy substrate beneath the sample with the raised outer rim may be the best explanation for the different histories. If we remove the submergence of the late 1980s from the record of T96-A-2, its HLS history is nearly identical to that of T96-A-1. If the apparent HLS change is not in fact due to a real subsidence, however localized, then it suggests that HLS can change by at least a few centimeters within a coral head for reasons unrelated to water level the effects of which are very localized. In either case, it bears on the precision of the microatoll HLS records from coral stratigraphy. Effects like these could introduce uncertainties of unknown magnitude. The best way to minimize the impact of these uncertainties is to ensure that sampled corals are representative of the main population of corals of similar age at the same site, and preferably to sample multiple corals at each site. We will assume in the following discussion, however, that sample T96-A-2 has been locally perturbed and that sample T96-A-1 represents the true HLS history of the site.

Recent Tectonic Deformation Above the Sumatran Subduction Zone

Submergence Rates. The Mentawai HLS curves indicate that HLS and relative sea level has been rising and the corals have been submerging over time. We calculated average submergence rates for the Mentawai microatolls based on the plots of HLS elevation versus time (Table 1 and Figure 10). We calculate the rates using three different methodsslope of the line fit by the method of least squares through HLS clips only, the best-fit line using HLS clips and HLS minima combined, and the net submergence rate using the difference in elevation of the oldest and youngest HLS. Fo- 
cusing only on HLS and ignoring the minimum HLS data may distort the true rate of submergence by preferentially excluding high HLS's that are not explicitly recorded in the coral. The rates calculated submergence rates using HLS's and minima combined yields rates higher by $1-2 \mathrm{~mm} / \mathrm{yr}$. The net submergence rates are generally lower by a few $\mathrm{mm} / \mathrm{yr}$ than the rates calculated using a least-squares fit, because the first and last decade of many of the records display nearly stable HLS elevations and because the youngest HLS reflects the recent 5-cm down-drop. In our discussion, we have used the average rates calculated by the first method-leastsquares fit to the HLS clips.

The submergence rates among the four Mentawai corals, excluding P96-K-2, range from $5.2 \mathrm{~mm} / \mathrm{yr}$ at site P96$\mathrm{J}-3$, in the South Pagai archipelago, to $9.5 \mathrm{~mm} / \mathrm{yr}$ at site Sd96-A, near Sanding Island. Rates using minimum HLS range from 6.2 to $10.8 \mathrm{~mm} / \mathrm{yr}$, and those calculated using first and last HLS range from 4.1 to $7.1 \mathrm{~mm} / \mathrm{yr}$. P96-K-2, as suggested by its morphology and HLS history, has a lower rate of submergence of $4.2 \mathrm{~mm} / \mathrm{yr}$ from HLS only (4.6 and $3.2 \mathrm{~mm} / \mathrm{yr}$ from the other calculations). The submergence rates from the Tikos samples bear out the morphological and stratigraphic suggestion of sea-level stability (see Fig. 10 and Table 1). Using HLS impingements alone, T96-A-1 appears to have emerged at a rate of $0.9 \mathrm{~mm} / \mathrm{yr}$ while T96-A-2, which may be disturbed, has a submergence rate of 1.4 $\mathrm{mm} / \mathrm{yr}$.

This comparison of submergence rates from two corals from the same site, which show a difference in rate of slightly more than $2 \mathrm{~mm} / \mathrm{yr}$, suggest that uncertainties of 3 $\mathrm{mm} / \mathrm{yr}$, at an estimated $95 \%$ confidence limit, might be applied to microatoll-derived submergence rates. Although we have described why it is quite possible that this difference is due to a local disturbance of one of the microatolls, we have not proven it. So we allow the possibility that the difference in calculated rates is a measure of the inherent uncertainty in a site's rate of submergence. Furthermore, rates calculated in three different ways yield the same values within $\pm 2-3 \mathrm{~mm} / \mathrm{yr}$. So, we consider that a conservative estimate of uncertainty in estimating submergence rates might be $2-3 \mathrm{~mm} / \mathrm{yr}$.

Geographic Distribution of Submergence Rates. Each site within the Mentawai Islands shows signs of substantial submergence, with rates ranging from 4 to $10 \mathrm{~mm} / \mathrm{yr}$, while the Tikos Island site appears stable. The magnitude of average submergence rate appears to vary systematically with distance from the trench. The geographic distribution of submergence rates perpendicular to the trench can be illustrated by projecting the site locations onto a trench-orthogonal line and plotting the coral-derived submergence rates as a function of distance from the trench (Fig. 12). The uncertainty that we have assigned to each data point $( \pm 3 \mathrm{~mm} / \mathrm{yr}$ at the $95 \%$ confidence limit) is a conservative measure of the imprecision of the measurements.

In general, the calculated submergence rates increase trenchward (see Table 1 and Fig. 12). This is especially clear in comparing the island sites to the mainland sites. Tikos Island, about $235 \mathrm{~km}$ from the trench, may be emerging at about $1 \mathrm{~mm} / \mathrm{yr}$ (see Fig. 10). At site P96-K, about $128 \mathrm{~km}$ from the trench, submergence is occurring at about $4 \mathrm{~mm} /$ yr. At site P96-J-3, about $5 \mathrm{~km}$ closer to the trench, submergence is slightly more rapid, about $5 \mathrm{~mm} / \mathrm{yr}$. At 121 and $119 \mathrm{~km}$ from the trench, sites Sd96-C-1 and P96-B-2 are experiencing submergence rates of about 8 and $7 \mathrm{~mm} / \mathrm{yr}$, respectively. Site Sd96-A, $123 \mathrm{~km}$ from the trench and submerging at the highest rate of $9.5 \mathrm{~mm} / \mathrm{yr}$, does not fit this trend of trenchward increase in rates.

There is also an indication that a gradient of about 3 $\mathrm{mm} / \mathrm{yr}$ may exist across the 7-km width of the island sites. This gradient is within the errors that we have assigned to each data point, so we cannot be sure of its existence. Furthermore, the gradient may be a function of our projecting the points onto a single plane. Some or all of the apparent gradient may be a function of trench-parallel variation in rate. Nevertheless, the gradient is qualitatively consistent with field observations of coral morphology. Microatolls on the southwest (trenchward) side of the islands typically have

Table 1

Coral-Derived Submergence Rates

\begin{tabular}{|c|c|c|c|c|c|}
\hline Site & $\begin{array}{l}\text { Distance from } \\
\text { Trench }(\mathrm{km})^{*}\end{array}$ & $\begin{array}{l}\text { Coral Dimensions } \\
\mathrm{D} ; \mathrm{H} ; \mathrm{RH}(\mathrm{cm}) \dagger\end{array}$ & $\begin{array}{l}\text { Submergence Rate, } \\
\text { HLS only }(\mathrm{mm} / \mathrm{yr})\end{array}$ & $\begin{array}{c}\text { Submergence Rate, } \\
\text { HLS and Minima } \neq(\mathrm{mm} / \mathrm{yr})\end{array}$ & $\begin{array}{c}\text { Submergence Rate, } \\
\text { First/Last HLS (mm/yr) }\end{array}$ \\
\hline P96-B & $110.7(119.1)$ & $\sim 110 ; \sim 65 ; \sim 20$ & 7.2 & 9.6 & 5.8 \\
\hline Sd96-C & $111.6(120.6)$ & $185 ; 75 ; 30-35$ & 7.7 & 8.4 & 5.8 \\
\hline P96-J & $112.7(122.6)$ & $240 ; 45 ; \sim 25$ & 5.2 & 6.2 & 4.1 \\
\hline Sd96-A & $113.4(122.9)$ & $\sim 250 ; \sim 50 ; \sim 40$ & 9.5 & 10.8 & 7.1 \\
\hline P96-K & $118.2(128.2)$ & $92 ; 22 ; 10$ & 4.2 & 4.6 & 3.2 \\
\hline T96-A-1 & 235 & $\sim 300 ; \sim 20 ; 0$ & -0.9 & 1.0 & -2.3 \\
\hline T96-A-2 & 235 & $\sim 300 ; \sim 30 ; 4$ & 1.4 & 0.8 & 0.6 \\
\hline
\end{tabular}

*Distances measured orthogonally from each site to the trench itself. Distances in parentheses are measured from sites to a line approximating the strike of the trench.

$\dagger \mathrm{D}$, diameter; $\mathrm{H}$, height above substrate; $\mathrm{RH}$, rim height above central flat.

$\ddagger$ Minima included only after the first HLS impingement. 


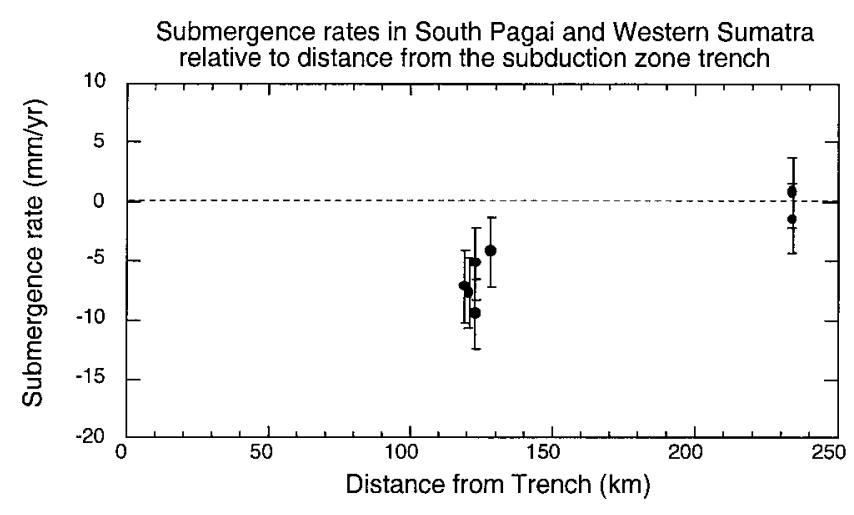

Figure 12. Submergence rates derived from stratigraphic analysis of coral microatolls from the Mentawai Islands and the west coast of Sumatra plotted as a function of distance from the subduction-zone trench. Distances are measured normal to the trench at each site.

higher raised rims than those on the northeast (landward) side (Zachariasen, 1998).

Elastic Dislocation Modeling of Interseismic Deformation. The high rates of submergence observed in the Mentawai Islands, the difference in rate between islands and coast, the tectonic setting of Western Sumatra, and the lack of similar submergence at non-tectonically active sites in the Indian Ocean suggest that this submergence is primarily tectonic and is caused by vertical deformation of the Southeast Asian plate near the plate boundary.

Regional vertical deformation at the surface over a subduction zone is often a result of subduction-related displacement in the subsurface, primarily along the plate interface. Our data are too sparse to rigorously model the source of vertical interseismic deformation, but we can place constraints on the source. Most importantly, almost none of the deformation is permanent. As we already noted, the presence throughout the area of mid-Holocene microatolls only a meter or two above modern, living microatolls demonstrates that net vertical motion in the past few millennia has been near zero (Zachariasen, 1998). If the rates that we have calculated for the past few decades characterized rates over the past few millennia, these mid-Holocene microatolls would now reside 25 to $50 \mathrm{~m}$ below sea level. Thus, we can ascribe almost all of the vertical deformation of the past few decades to processes related to the accumulation and relief of strain above the subduction interface. And we can be confident that strain accumulation at our sites must, over the millennia, nearly equal strain relief.

The most recent large earthquake in the region of South Pagai Island was the giant (ca. $M_{\mathrm{w}}$ 9) earthquake of 1833 (Zachariasen et al., 1999). Newcomb and McCann (1987) used reports of tsunami damage and shaking intensity as well as structural evidence to constrain the source of the earthquake to a 550-km length of the subduction interface, cen- tered approximately on the Pagai Islands. Zachariasen et al., (1999) have shown that South Pagai and neighboring islands emerged 1 to $2 \mathrm{~m}$ during that event. Their modeling suggests that the slip in that event is consistent with almost all the interseismic convergent strain being stored elastically and released coseismically. Furthermore, just as the modern rate of submergence of the islands appears to increase trenchward, the coseismic emergence in 1833 increased trenchward. Thus, qualitatively, our observations of vertical displacement are consistent with a model of interseismic strain accumulation and seismic strain relief.

To obtain a more quantitative estimate of the source of interseismic deformation, we use a simple elastic dislocation model, after Savage (1983), to describe the vertical displacement at the surface above the subduction zone. In this model, the plate interface is assumed to be a planar fault in an elastic half-space. The main thrust zone of the subduction interface is assumed to be locked interseismically, while the downdip section continues to slip. The locked section of the overriding plate is pulled downward with the subducting plate as it sinks into the asthenosphere, causing submergence over the locked section and producing an uplifted bulge landward of the locked portion. The nature and magnitude of the vertical displacement of the surface at any site over the interface is dependent on the dip of the subduction zone, the amount of slip, the down-dip width of the locked zone, and the distance from the trench. The model is predicated on the basic assumption that interseismic deformation recovers coseismic deformation, in other words that permanent strains are small compared to elastic strains. Insofar as the system behaves elastically, places with coseismic uplift should show interseismic subsidence and vice versa.

The simplest elastic dislocation model of this type uses a single dipping plane to represent the locked subduction interface. We initially tried using a single-plane model, with a dip of $12^{\circ}$ for the fault — earthquake focal mechanisms for several subduction-zone earthquakes that occurred near Sipora Island in the 1990s suggest a rupture surface that dips between $8^{\circ}$ and $12^{\circ}$ (Harvard CMT catalogue)—and a slip rate on the interface of $50 \mathrm{~mm} / \mathrm{yr}$, the orthogonal component of the full plate convergence rate of $67 \mathrm{~mm} / \mathrm{yr}$ (Tregoning et al., 1994). We found that we could not model both the submergence rates on the islands and the stability on the coast with a locked interface of reasonable proportions on a planar fault and slip rates near the plate rates (Zachariasen, 1998).

To try to improve the model, we introduced a more realistic fault geometry that allows for variations in fault dip. The dip of the Wadati-Benioff zone increases from $8^{\circ}$ to $12^{\circ}$ at the outer-arc to about $50^{\circ}$ at the volcanic arc (Newcomb and McCann, 1987; Fauzi et al., 1996). Figure 13 depicts one plausible scenario, in which the interface consists of three contiguous planes, with dips progressively increasing away from the trench. In this case, we use the shallower dip of $8^{\circ}$ suggested by focal-mechanism solutions for the plane closest to the trench. The dips on the other segments are left 

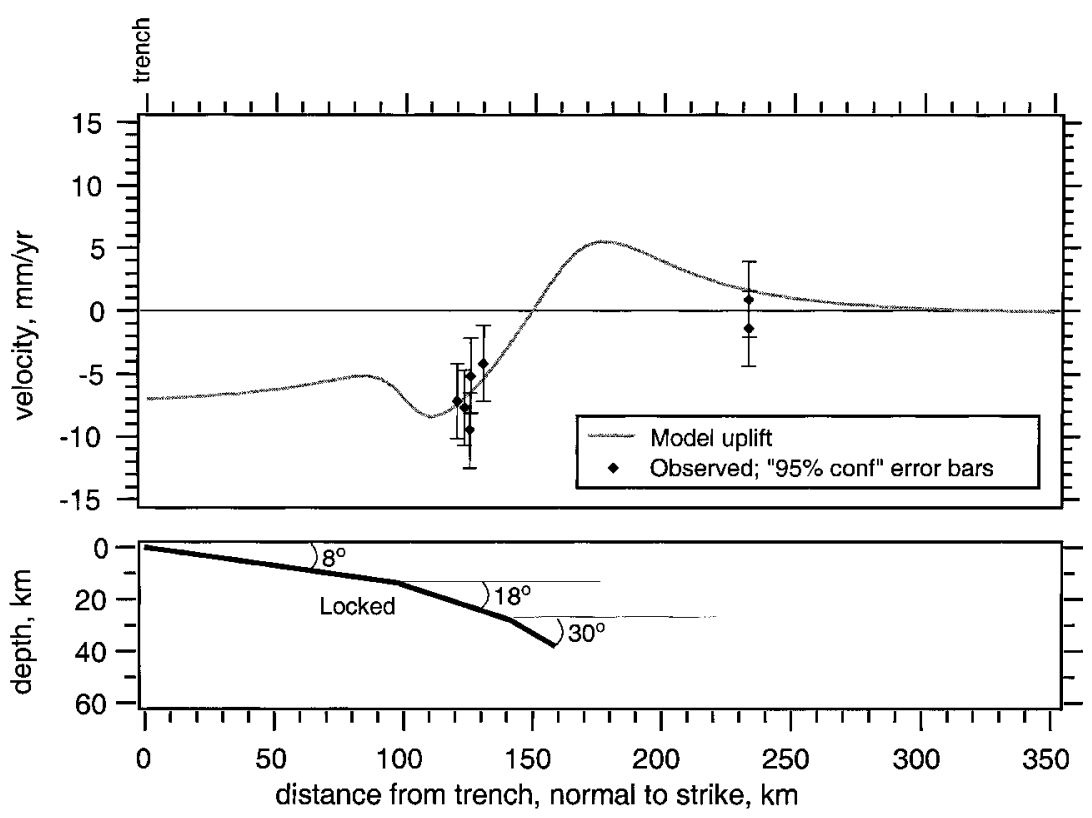

Figure 13. Elastic dislocation modeling of the pattern and magnitude of interseismic vertical displacement rates at the surface above a subduction zone as a function of distance from the trench (after Savage, 1983). The subduction interface is modeled as a three-plane surface. The plane nearest the trench has an $8^{\circ}$ dip, constrained by focal mechanisms of local earthquakes; the dips of the other planes are unconstrained except to steepen with distance from the trench. The grey line shows the vertical displacement rates at the surface over the subduction interface if $50 \mathrm{~mm} / \mathrm{yr}$, the trenchorthogonal component of the full plate convergence rate, is used for the interplate slip rate, and the shallow portion of the plate interface is locked to about $40 \mathrm{~km}$ depth while the downdip portions slip freely. The observed submergence rates derived from the corals are also plotted with uncertainties. as variable parameters but are consistent with the change in dip of the Wadati-Benioff zone. The widths of the locked portions are also variable parameters. We again use the trench-orthogonal component of the full plate convergence rate $(50 \mathrm{~mm} / \mathrm{yr})$ as the interplate slip rate. Using this progressively steepening-dip model, we can model the observed rates reasonably well. The modeled curve fits the magnitude of the observed submergence rates at the Mentawai Islands. It has a steep gradient across the Mentawai region, close to what we observe. It also accommodates the Tikos data within the uncertainties, which the single dip model failed to do.

The solution in Figure 13 is by no means unique, given the limited constraints of our data set, and numerous other scenarios are possible. Further massaging of the parameters, increasing, for example, the number of planar segments comprising the locked interface, could likely produce a better fit without being more physically significant. The model is also overly simple. It does not incorporate realistic kinematic behavior for the downgoing slab, such as a locked shallow interface, aseismic slip down-dip of the coseismic interface, regional viscoelastic response to large subduction events, and the sinking into the mantle asthenosphere of the oceanic slab (Thatcher, 1984; Thatcher and Rundle, 1984). Furthermore, it is only a two-dimensional model. It does not take into account trench-parallel variations. Tikos Island is about $150 \mathrm{~km}$ southeast along strike of the subduction interface from the Pagai Islands (see Fig. 1), so it is conceivable that displacement patterns would differ between the two latitudes. It does not account for any displacement occurring on secondary, upper-plate structures such as the Mentawai Fault, a 600-km-long fault that strikes parallel to the trench and is located between the Mentawai Islands and the west coast of Sumatra (Diament et al., 1992). Incorporating these features is beyond the scope of this article, and beyond the constraints provided by our data.

\section{Discussion}

\section{Using Corals as a Geodetic Measurement Tool}

Coral slab stratigraphy provides a means to measure sea-level changes on annual to decadal time scales. This is adequate for the recovery of interseismic rates of vertical motion and changes in those rates. Thus, microatoll stratigraphy has the potential to extend instrumental geodetic records far into the past and address geodetic questions relevant to the subduction-zone strain accumulation and relief. For example, geodetic observations of modern tectonic displacements elsewhere have revealed that in some cases vertical displacement rates above subduction zones are greater just prior to and just following a coseismic rupture (Savage and Thatcher, 1992).

Our results suggest that coral microatolls could be used to address whether this is generally true, by providing a paleogeodetic record for subduction zones throughout tropical regions. Assuming uncertainties in the rates of $2-3 \mathrm{~mm} / \mathrm{yr}$, for corals submerging at $7 \mathrm{~mm} / \mathrm{yr}$, an increase in submergence rate of $30 \%-50 \%$ should be recognizable in a 50-year record. The longer the record, the more evident such changes would be, as short-term oceanographic fluctuations that might affect the average signal would be less significant over longer time periods.

\section{Interseismic Deformation on the Subduction Zone}

Our elastic dislocation modeling of interseismic deformation in Sumatra (see Fig. 13), though underconstrained, provides some insight into the behavior of the subduction 
zone. First, it suggests that interseismic elastic strain accumulation across the subduction interface could account for most of the observed vertical displacements that have occurred above this portion of the subduction zone over the past few decades. The 2-mm/yr uplift at the coast of Sumatra is within the range of possible rates we determined from the two coral slabs from Tikos Island, but it is nevertheless greater than we suspect from the morphology of all the coral heads we observed at Tikos Island and elsewhere along the coast. Whether this indicates a real deviation from elasticstrain accumulation or is merely a by-product of an underconstrained model cannot be determined from data currently available. It seems likely, however, that such accumulation is occurring and does explain most of the observations. This is consistent with other observations from the region. Recent GPS measurements also show that large strains are accumulating (Prawirodirjo et al., 1997). Furthermore, the occurrence of an $M 9$ earthquake in the region in 1833 strongly suggests that such strains do accumulate and are released seismically in large earthquakes (Newcomb and McCann, 1987; Zachariasen et al., 1999).

Second, the modeling suggests that the subduction interface is fully coupled. The whole trench-orthogonal component of the plate convergence rate, $50 \mathrm{~mm} / \mathrm{yr}$, must be used to model the magnitude of the submergence rates observed in the Mentawai Islands. Any incomplete coupling between the plates would result in lower submergence rates than those observed on the islands. This is also consistent with results from recent GPS studies, which indicate that convergence rates in this area are as high as our estimate and that this portion of the subduction zone is completely coupled (Prawirodirjo et al., 1997).

\section{Episodic versus Gradual Submergence}

The records from the Mentawai Islands suggest that interseismic submergence there may be episodic rather than gradual. Unlike the hypothetical record of impingements in Figure 4, the Mentawai records display long intervals, such as the period of the 1960s and 1970s, devoid of HLS clips separated by periods with numerous HLS clips (see Fig. 10). When HLS clips resumed in the samples in the early 1980s, HLS elevations were about 20 to $30 \mathrm{~cm}$ above the levels of the late 1950s. If the Mentawai Islands were subsiding regularly at high rates, Figure 4(c) suggests that microatolls would tend to record singular HLS clips separated by several years of unimpeded growth. We see a long period of unclipped upward growth (the 1960s and 1970s) that separates two periods of frequent clips (the 1950s and the 1980s-1990s).

Figure 14 illustrates the difference in the expected pattern of HLS clips between the cases of gradual and episodic submergence superimposed on oceanographically induced sea-level fluctuations if the oceanographic fluctuations are about twice the size of the submergence episodes and the fluctuations are perfectly regular (represented by a sine wave). The gradual case (Fig. 14(a)) shows perfectly regular HLS clips and a uniform submergence rate, whereas the ep- a.
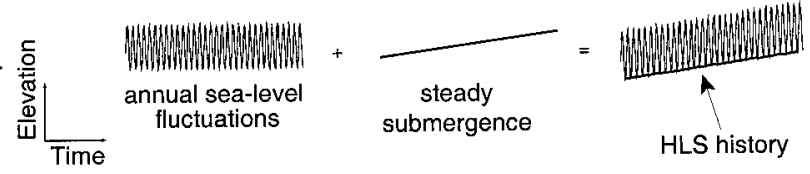

b.
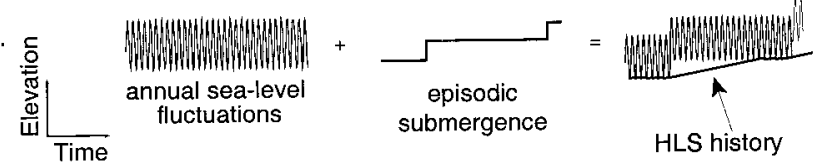

Figure 14. Hypothetical effects of interseismic deformation on HLS records. The sine waves represent annual nontectonic fluctuations of sea level. (a) Oceanographically induced sea-level fluctuations, modeled as a sine wave, with gradual tectonic subsidence. The dotted line in the combined signal is the coral growth curve, showing regular HLS clips and small emergences. (b) Oceanographically induced sea-level fluctuations with sudden, episodic submergence events. The coral growth curve displays periods of HLS stability followed by periods devoid of HLS clips.

isodic case (Fig. 14(b)) shows multiple rapid HLS clips with little elevation change, followed by a long period without any HLS impingements, then another period with many clips. The latter scenario is similar to that observed in most of the slabs from the outer-arc islands.

We cannot rule out the possibility that the submergence is gradual and the pattern of HLS clips is due more to oceanographic variability than tectonic variability. Zachariasen (1998) uses an extended record of actual sea-level fluctuations to demonstrate that the difference between the episodic and gradual cases in the resulting HLS records is less evident than in Figure 14 and that the distinction between episodic submergence and gradual submergence is clearer if the size of the submergence event is greater than the interannual variability in lowest low tides. Fluctuations in mean daily tides at Padang between 1987 and 1990 had a 30-cm range (UHSLC database). However, the small interannual variability of HLS clips in the Tikos Island records (see Fig. 10) supports the belief that annual fluctuations in lowest low water are much smaller than the $20-$ to $30-\mathrm{cm}$ amplitude of submergence event that we may see in the Mentawai samples.

Four decades of subdued annual swings in lowest low water might also explain the lack of HLS clips during the 1960s and 1970s, however. If lowest low water had been consistently $25 \mathrm{~cm}$ or so higher since about 1960, HLS clips would have been avoided until the 1980s, and HLS would now be about $30 \mathrm{~cm}$ higher than it was in the 1950s, all without any tectonic activity. This ad hoc hypothesis is difficult to defend, however, given the lack of evidence for such an oceanographic change in the early 1960s. It does, however, caution us that our paleogeodetic instrument can be influenced by more than just tectonic changes and that our 
interpretations are preliminary.

An alternative tectonic explanation of the Mentawai records is something between purely episodic and perfectly steady submergence, where submergence is ongoing but at variable rates. For example, HLS stability might have characterized the decades of the 1950s, 1980s, and 1990s, whereas rapid but gradual submergence typified the 1960s and 1970s. Average rates of submergence would have been 11 to $13 \mathrm{~mm} / \mathrm{yr}$ during these two decades. It is not clear that one can definitively distinguish between episodic and steady submergence; it is less likely that one could distinguish the HLS signature produced from a sudden submergence event and a period of submergence at an increased rate. As long as the submergence rate outpaces the coral growth rate, HLS clips will be minimized. In a submerging environment, the real nature of a relative sea-level change may never be known from the coral record alone. To determine if the interseismic vertical displacement over the Sumatran subduction zone is occurring episodically or gradually, it would be best to examine microatolls in the region of interseismic uplift, since emerging corals offer a much more precise HLS record (Zachariasen, 1998).

\section{Conclusions}

We have shown that coral microatolls can be used to extend records of vertical deformation into the preinstrumental past. Our data indicate that the Mentawai Islands, 119 to $128 \mathrm{~km}$ from the trench, have been submerging at average rates of several millimeters per year over the past few decades. During this same period, the western mainland coast of Sumatra, about $235 \mathrm{~km}$ from the trench, has been stable. The submergence appears to have occurred primarily between the late 1950s and early 1980s, but we cannot tell whether it occurred uniformly during this period or in one or more aseismic events.

An examination of the variation in submergence rate across the subduction zone indicates that it is broadly consistent with observations of interseismic deformation at other subduction zones. Although the data are as yet too sparse for rigorous modeling, a simple elastic dislocation model suggests that most of the observed vertical displacement can be explained by interseismic elastic strain accumulation on the subduction interface. Further, the model suggests that the subduction zone in this region is completely coupled. Both these results are consistent with recent GPS data indicating full coupling and with paleoseismic data that suggest significant accumulated strain is released in large earthquakes.

Slight misfits of the model from the observations and indications of possible episodic submergence events imply that deformation processes other than uniform interseismic elastic strain accumulation may be responsible for a portion of the submergence observed on the islands. Possible processes include episodic, aseismic slip on the shallowest portions of the interface or displacement on upper-plate structures. Slip on a portion of the subduction interface trenchward of the islands is plausible, because it could pro- duce submergence of the Mentawai Islands, without coincident vertical displacement of the mainland coast. This mechanism is attractive because it plausibly could be intermittent and aseismic. Such an event or events would necessarily have been aseismic, since there is no record of earthquakes larger than about magnitude six in this region during the 1950s, 1960s, or 1970s (Newcomb and McCann, 1987). However, if we attribute a large portion of the submergence to aseismic slip on the subduction interface trenchward of the Mentawai Islands, we are left without long-term interseismic accumulation of strain in the region. That is, the subducting oceanic slab would be decoupled from the overriding plate, a suggestion that is not supported by GPS or paleoseismic data. Therefore, we think it likely that elastic strain accumulation accounts for most of the observed displacement. The explanation for the possible episodic nature of the submergence remains unclear in this context.

The data are not complete enough at this point to rigorously model interseismic deformation over the interface as has been done with tide gauge and leveling data near other subduction zones. It is likely, however, that coral microatolls can provide similar data that may eventually permit robust quantitative modeling. Stratigraphic analysis of microatolls holds great promise for yielding a dense array of relative sea-level and vertical-displacement records, which could ultimately help define the nature of subduction-related deformation in the hanging wall of a large subduction zone.

\section{Acknowledgments}

This work was supported by NSF grant NSF EAR-9628301. We are very grateful to John Beavan and Tim Melbourne for help with the elastic dislocation modeling. Mark Simons, Mike Gurnis, and Joann Stock offered valuable assistance and helpful comments. We thank Anne Lilje and Tony Soeller for computer and GIS assistance and Jim O'Donnell for library assistance. Lisa Grant, Yoko Ota, Paolo Pirazzoli, and an anonymous reviewer provided reviews that greatly improved this manuscript. We also thank the owner and crew of the Dani Putra, our Indonesian field vessel: Daniel Madre, Tobing, Doni, Bambang, Rapit, and As; and LIPI field assistants: Nono, Anto, Arief, Sri, and Dudi. Caltech Seismological Laboratory contribution number 8486 .

\section{References}

Buddemeier, R. W., J. E. Maragos, and D. W. Knutson (1974). Radiographic studies of reef coral exoskeletons: rates and patterns of coral growth, J. Exp. Mar. Biol. Ecol. 14, 179-200.

Budhitrisna, T., and S. Andi Mangga (1990). Geology of the Pagai and Sipora Quadrangle, Sumatra, Pusat Penelitian dan Pengembangan Geologi, Bandung, 1-21.

Diament, M., H. Harjono, K. Karta, C. Deplus, D. Dahrin, M. T. Zen Jr., M. Gerard, O. Lassal, A. Martin, and J. Malod (1992). Mentawai fault zone off Sumatra: a new key to the geodynamics of western Indonesia, Geology 20, 259-262.

Edwards, R. L., F. W. Taylor, and G. J. Wasserburg (1988). Dating earthquakes with high-precision thorium-230 ages of very young corals, Earth and Planetary Science Letters 90, 371-381.

Edwards, R. L. (1988). High precision thorium-230 ages of corals and the timing of sea level fluctuations in the late quaternary, Ph.D. Thesis, California Institute of Technology, Pasadena, California, 352 pp.

Fauzi, R. McCaffrey, D. Wark, Sunaryo, and P. Y. Prih Harydi (1996). 
Lateral variation in slab orientation beneath Toba Caldera, northern Sumatra, Geophys. Res. Lett. 23, 443-446.

Fitch, T. J. (1972). Plate convergence, transcurrent faults, and internal deformation adjacent to Southeast Asia and the Western Pacific, J. Geophys. Res. 77, 4432-4460.

Inouchi, N., and H. Sato (1975). Vertical crustal deformation accompanied with the Tonankai earthquake of 1944, Bull. Geogr. Surv. Inst. Tokyo 21, 10-18.

Katili, J. A., and F. Hehuwat (1967). On the occurrence of large transcurrent earthquakes in Sumatra, Indonesia, Osaka University Journal of Geoscience 10, 5-17.

Kato, T., and K. Tsumura (1979). Vertical land movement in Japan as deduced from tidal record, Bull. Earthquake Res. Inst. Tokyo Univ. 54, 559-628 (in Japanese).

Knutson, D. W., R. W. Buddemeier, and S. V. Smith (1972). Coral chronometers: seasonal growth bands in reef corals, Science 177, 270272.

Lambeck, K., and M. Nakada (1990). Late Pleistocene and Holocene sealevel change along the Australian coast, Palaeogeograph. Palaeoclimatol. Palaeoecol. 89, 143-176.

Lough, J. M., and D. J. Barnes (1990). Possible relationships between environmental variables and skeletal density in a coral colony from the central Great Barrier reef, J. Exp. Mar. Biol. Ecol. 134, 221-241.

McCaffrey, R. (1991). Slip vectors and stretching of the Sumatran fore arc, Geology 19, 881-884.

McCaffrey, R. (1992). Oblique plate convergence, slip vectors, and forearc deformation, J. Geophys. Res. 97, 8905-8915.

Newcomb, K. R., and W. R. McCann (1987). Seismic history and seismotectonics of the Sunda Arc, J. Geophys. Res. 92, 421-439.

Peltier, W. R., and A. M. Tushingham (1991). Influence of glacial isostatic adjustment on tide gauge measurements of secular sea level change, J. Geophys. Res. 96, 6779-6796.

Plafker, G. (1965). Tectonic deformation associated with the 1964 Alaska earthquake, Science 148, 1675-1687.

Plafker, G., and M. Rubin (1967). Vertical tectonic displacements in south central Alaska during and prior to the great 1964 earthquake, Geosci. Osaka City Univ. 10, 53-66.

Prawirodirdjo, L., Y. Bock, R. McCaffrey, J. Genrich, E. Calais, C. Stevens, S. S. O. Puntodewo, C. Subarya, J. Rais, P. Zwick, and Fauzi (1997). Geodetic observations of interseismic strain segmentation at the Sumatra subduction zone, Geophys. Res. Lett. 24, no. 21, 2601-2604.

Priess, K., B. A. Thomassin, G. A. Heiss, W.-C. Dullo, and G. Camoin (1995). Variabilite de la croissance de Porites massifs dans les recifs coralliens de Mayotte, C.R. Acad. Sci. Paris, Sciences de la vie 318, $1147-1154$.

Sato, H. (1970). Crustal movements associated with the 1944 Tonankai Earthquake, J. Geol. Soc. Japan 15, 177-180 (in Japanese).

Savage, J. C. (1983). A dislocation model of strain accumulation and release at a subduction zone, J. Geophys. Res. 88, 4984-4996.

Savage, J. C. (1995). Interseismic uplift at the Nankai subduction zone, southwest Japan, 1951-1990, J. Geophys. Res. 100, 6339-6350.

Savage, J. C., and G. Plafker (1991). Tide gauge measurements of uplift along the south coast of Alaska, J. Geophys. Res. 96, 4325-4335.

Savage, J. C., and W. Thatcher (1992). Interseismic deformation at the Nankai trough, Japan, subduction zone, J. Geophys. Res. 97, 1111711135 .

Scoffin, T. P., and D. R. Stoddart (1978). The nature and significance of microatolls, Philosophical Transactions of the Royal Society London $B, \mathbf{2 8 4}, 99-122$.

Sieh, K. (1996). The repetition of large earthquakes, Proc. Natl. Acad. Sci. USA 93, 3764-3771.

Stoddart, D. R., and T. P. Scoffin (1979). Microatolls: review of form, origin and terminology, Atoll Res. Bull. 228, 1-17.

Taylor, F. W., C. Frohlich, J. Lecolle, and M. Strecker (1987). Analysis of partially emerged corals and reef terraces in the central Vanuatu arc: comparison of contemporary coseismic and nonseismic with Quaternary vertical movements, J. Geophys. Res. 92, 4905-4933.
Taylor, F. W., R. L. Edwards, and G. J. Wasserburg (1990). Seismic recurrence intervals and timing of aseismic subduction inferred from emerged corals and reefs of the central Vanuatu (New Hebrides) frontal arc, J. Geophys. Res. 95, 393-408.

Taylor, F. W., J.-Y. Collot, H. G. Greene, L. B. Stokking, K. Akimoto, M. V. S. Ask, P. E. Baker, L. Briqueu, T. Chabernaud, M. G. Collins, M. Coltorti, M. A. Fisher, T. Hasenaka, M. A. Hobart, A. Krammer, J. N. Leonard, J. B. Martin, J. I. Martinez-Rodriguez, S. Menger, M. Meschede, B. Pelletier, R. C. B. Perembo, T. M. Quinn, P. Reid, W. R. Riedel, P. Roperch, T. S. Staerker, X. Zhao, L. H. E. Dearmont (1992). Quaternary vertical tectonics of the central New Hebrides island arc Proceedings of the Ocean Drilling Program, Vanuatu (New Hebrides), covering Leg 134 of the cruises of the drilling vessel JOIDES Resolution, Port of Townsville, Queensland, Australia, to Suva, Republic of Fiji, sites 827-833, 11 October 1990-17 December 1990. Proceedings of the Ocean Drilling Program, Part A: Initial Reports 134, 33-42.

Thatcher, W. (1984). The earthquake deformation cycle at the Nankai trough, Southwest Japan, J. Geophys. Res. 89, 3087-3101.

Thatcher, W., and J. B. Rundle (1984). A viscoelastic coupling model for the cyclic deformation due to periodically repeated earthquakes at subduction zones, J. Geophys. Res. 89, 7631-7640.

Tregoning, P., F. K. Brunner, Y. Bock, S. S. O. Puntodewo, R. McCaffrey, J. F. Genrich, E. Calais, J. Rais, and C. Subarya (1994). First geodetic measurement of convergence across the Java Trench, Geophys. Res. Lett. 21, 2135-2138.

Vita-Finzi, C., and B. Situmorang (1989). Holocene coastal deformation in Simeleue and Nias, Indonesia, Marine Geology 89, 153-161.

Weber, J. N., and E. W. White (1977). Caribbean reef corals Monastrea annularis and Monastrea cavernosa-long-term growth data as determined by skeletal X-radiography, Am. Assoc. Petrol. Geol. 4, 171179.

Woodroffe, C., and R. McLean (1990). Microatolls and recent sea level change on coral atolls, Nature 344, 531-534.

Woodroffe, C., R. McLean, and E. Wallensky (1990a). Darwin's coral atoll: geomorphology and recent development of the Cocos (Keeling) Islands, Indian Ocean, National Geographic Research 6, 262-275.

Woodroffe, C., R. McLean, H. Polach, and E. Wallensky (1990b). Sea level and coral atolls: late Holocene emergence in the Indian Ocean, $G e$ ology 18, 62-66.

Woodroffe, C. D., H. H. Veeh, A. C. Falkland, R. F. McLean, and E. Wallensky (1991). Last interglacial reef and subsidence of the Cocos (Keeling) Islands, Indian Ocean, Marine Geology 96, 137-143.

Zachariasen, J. (1998). Paleoseismology and paleogeodesy of the Sumatran Subduction Zone: a study of vertical deformation using coral microatolls, Ph.D. Thesis, California Institute of Technology, Pasadena, California, $418 \mathrm{pp}$.

Zachariasen, J., K. Sieh, R. L. Edwards, F. W. Taylor, and W. S. Hantoro (1999). Pre- and coseismic vertical displacement associated with the giant 1833 Sumatran subduction earthquake: evidence from coral microatolls, J. Geophys. Res. 104, 895-919.

Seismological Laboratory

California Institute of Technology

Pasadena, California, 91125

(J. Z., K. S.)

Institute for Geophysics

University of Texas at Austin

4412 Spicewood Springs Rd., Bldg. 600

Austin, Texas 78759-8500

(F. W. T.)

Puslitbang Geoteknologi

Lembaga Ilmu Pengetahuan Indonesia

Bandung, Indonesia

(W. S. S.)

Manuscript received 27 January 1998. 